\title{
Bias and standard error for social reciprocity
}

\section{measurements}

Antonio Solanas, David Leiva, and Lluís Salafranca

Department of Behavioural Sciences Methods

Faculty of Psychology, University of Barcelona

AUTHORS' NOTE

This research was partially supported by the Ministerio de Educación y Ciencia, grants SEJ2005-07310-C02-01/PSIC, and by the Comissionat per a Universitats i Recerca of the Departament d'Innovació, Universitats i Empresa of the Generalitat de Catalunya and the European Social Fund, grants $2005 S G R 00098$ and $2008 F I C 00156$.

Address correspondence to: Antonio Solanas, Departament de Metodologia de les Ciències del Comportament, Facultat de Psicologia, Universitat de Barcelona, Passeig de la Vall d'Hebron, 171.08035-Barcelona, Spain. E-mail: antonio.solanas@ub.edu 


\begin{abstract}
The directional consistency and skew-symmetry statistics have been proposed as global measurements of social reciprocity. Although both measures can be useful for quantifying social reciprocity, researchers need to know whether these estimators are biased in order to assess descriptive results properly. That is, if estimators are biased, researchers should compare actual values with expected values under the specified null hypothesis. Furthermore, standard errors are needed to enable suitable assessment of discrepancies between actual and expected values. This paper aims to derive some exact and approximate expressions in order to obtain bias and standard error values for both estimators for round-robin designs, although the results can also be extended to other reciprocal designs.
\end{abstract}

\title{
Keywords
}

Directional consistency statistic, skew-symmetry statistic, bias and standard error, dyadic designs.

\section{Acknowledgments}

The authors would like to thank Dr. David A. Kenny and an anonymous reviewer for their useful comments and suggestions, which contributed to improve the manuscript. 
Several statistical techniques for quantifying social reciprocity have been proposed in recent decades, and the best-known is probably the Social Relations Model (SRM: Kenny \& La Voie, 1984; Warner, Kenny, \& Stoto, 1979). Indeed, the SRM has often been used in social psychology studies, for instance in family assessment research (Cook, 2005; Cook \& Kenny, 2004; Delsing, Oud, De Bruyn, \& Van Aken, 2003), interpersonal perception (Albright, Kenny, \& Malloy, 1988; Kenny \& De Paulo, 1993; Malloy \& Albright, 1990), and developmental psychology (Miller \& Byrnes, 1997; Whitley, Ward, \& Snyder, 1984). Although the SRM allows social researchers to compute dyadic and generalized reciprocity (Kenny \& La Voie, 1984; Kenny \& Nasby, 1980, Warner et al., 1979), it does not provide an absolute and global measure of social reciprocity among all individuals. That is, a measure of social reciprocity founded on the discrepancy between the behaviour each individual addresses to others and what is received in return. With respect to inferential purposes, several statistical procedures have been proposed for testing round-robin data in the SRM (Lashley \& Bond, 1997).

In this regard the directional consistency index (DC: van Hooff \& Wensing, 1987) has been developed to obtain global social reciprocity measurements. The DC is a ratio that reflects the degree of symmetry in social interactions and it has been widely used by ethologists (Côté, 2000; Koenig, Larney, Lu, \& Borries, 2004; Pelletier \& FestaBianchet, 2006; Stevens, Vervaecke, de Vries, \& van Elsacker, 2005; Vervaecke, de Vries, \& van Elsacker, 1999; Vogel, 2005; Wittemyer \& Getz, 2007). The index is computed as follows: 


$$
D C=\frac{\sum_{i=1}^{n} \sum_{\substack{j=i+1 \\ j \neq i}}^{n}\left|x_{i j}-x_{j i}\right|}{N}, \quad N=\sum_{i=1}^{n} \sum_{\substack{j=1 \\ j \neq i}}^{n} x_{i j}, \quad 0 \leq D C \leq 1,
$$

where $x_{i j}$ denotes the number of behaviours that individual $i$ addresses to $j$. Note that the index is scaled between 0 and 1 , and takes values close to 0 if social relations are symmetrical and values near 1 if social relations are asymmetrical. It should also be noted that the DC index is only a global measure and is unable to obtain measures at dyadic or individual levels or to measure dyadic and generalized reciprocity. A test founded on Monte Carlo sampling has recently been proposed to obtain statistical significance for the DC statistic (Leiva, Solanas, \& Salafranca, 2008).

Another recent technique for quantifying social reciprocity (Solanas, Salafranca, Riba, Sierra, \& Leiva, 2006) is based on dyadic interactions, specifically on absolute differences between the amount of behaviour that each individual addresses to her/his partners and what she/he receives in return. Consequently, dyads are the unit of analysis and it is assumed that every individual is able to interact with all his/her partners. Several measurements at individual, dyadic and group levels can be obtained by means of this procedure. Furthermore, the technique also allows social researchers to obtain dyadic and generalized social reciprocity measures. The procedure decomposes any square sociomatrix $\mathbf{X}$ into its symmetrical and skew-symmetrical parts:

$$
\mathbf{X}=\frac{\mathbf{X}+\mathbf{X}^{\prime}}{2}+\frac{\mathbf{X}-\mathbf{X}^{\prime}}{2}=\mathbf{S}+\mathbf{K}
$$


where $\mathbf{S}$ and $\mathbf{K}$ denote symmetrical and skew-symmetrical matrices, respectively. The global index of skew-symmetry $\Phi$ can be obtained as follows:

$$
\Phi=\frac{\operatorname{tr}\left(\mathbf{K}^{\prime} \mathbf{K}\right)}{\operatorname{tr}\left(\mathbf{X}^{\prime} \mathbf{X}\right)}=\frac{\sum_{i=1}^{n} \sum_{\substack{j=1 \\ j \neq i}}^{n} k_{i j}^{2}}{\sum_{\substack{i=1 \\ j}}^{n} \sum_{\substack{j=1 \\ j \neq i}}^{n} x_{i j}^{2}}, \operatorname{tr}\left(\mathbf{X}^{\prime} \mathbf{X}\right)>0, \quad 0 \leq \Phi \leq .5 .
$$

Note that if $\Phi$ equals .5 , it corresponds to the maximum lack of reciprocity that can be achieved.

The substantive meaning of the DC and the skew-symmetry statistics is supposed to be adequately based on the distance between their minimum values and the outcome for available data. However, it should be noted that these comparisons would fail if both estimators were biased, and biased estimators have indeed been obtained for other quantifications of social interactions (Landau, 1951). Therefore, it is necessary to demonstrate whether the two estimators are unbiased, and if not, a mathematical expression for their bias should be obtained in order to make adequate substantive interpretations. Additionally, given that variability is another important feature of estimators, it is also necessary to derive exact or approximate mathematical expressions for the standard errors of the two statistics.

The main purpose of this paper is to obtain — at least - approximate mathematical expressions for the bias and standard error of the DC and the skew-symmetry estimators. Mathematical expressions for bias will allow social researchers to make both proper comparisons and suitable descriptions, while standard error expressions will 
enable them to take decisions regarding the relative distance between expected values under the specified null hypothesis and statistic values. Although this research was mainly intended to provide some analytical results for analysing data obtained from round-robin designs, the mathematical expressions can also be applied to other dyadic designs such as standard and block designs (Kenny, Kashy, \& Cook, 2006).

\section{The directional consistency index: Expected value and standard error}

The expected value of the DC estimator can be computed by

$$
E[D C]=\frac{1}{N} \sum_{i=1}^{n} \sum_{j=i+1}^{n} E\left[\left|x_{i j}-x_{j i}\right|\right]
$$

where $x_{i j}$ denotes the number of behaviours that individual $i$ addresses to $j$. In order to obtain this expected value it is first necessary to solve $E\left[\left|x_{i j}-x_{j i}\right|\right]$. It will be assumed that only one individual addresses behaviour to the other individual of the dyad in each social interaction between them. Thus, if $\pi_{i j}$ and $\pi_{j i}$ denote, respectively, the probability that individual $i$ addresses behaviour to individual $j$ and individual $j$ addresses behaviour to individual $i, \pi_{\mathrm{ij}}+\pi_{\mathrm{ji}}=1$. Furthermore, it is supposed that the outcome of every social interaction is independent of previous encounters and each dyad interaction does not depend on other dyadic outcomes. It is also assumed that the probability values $\pi_{i j}$ and $\pi_{j i}$ are constant during the observation period. This set of assumptions has been previously used to model dominance encounters (Appleby, 1983; Boyd \& Silk, 1983; Tufto, Solberg, \& Ringsby, 1998) and, although they are not always maintained in observational settings, these assumptions are likely to be approximately valid whenever 
social relations are steady during the observation period and outcomes are close to independence. It should be noted that these assumptions are also common in the SRM (Kenny et al., 2006; Warner et al., 1979). Under these assumptions a binomial probability function can be used to describe the random distribution that follows the number of behaviours for each individual in a dyad, $x_{i j}$. In what follows it will be denoted the number of recorded behaviours in each dyad by $\mathrm{c}_{\mathrm{ij}}=\mathrm{x}_{\mathrm{ij}}+\mathrm{x}_{\mathrm{ji}}, c_{i j}$ being equal to $c_{j i}$.

The expected value for the DC estimator can be computed as follows (see Appendix I):

$$
E[D C]=\frac{1}{N} \sum_{i=1}^{n} \sum_{j=i+1}^{n}\left(\sum_{k=0}^{m_{i j}} \operatorname{Pr}\left\{\left|x_{i j}-x_{j i}\right|=c_{i j}-2 k\right\}\left(c_{i j}-2 k\right)\right) .
$$

Figure 1 shows how the mathematical expectancy varies for several values of $\pi_{i j}$ and $c_{i j}$. For those conditions in which complete and moderate reciprocation is assumed, the frequency of interactions in dyads, $c_{i j}$, affects the mathematical expectancy of the DC. Note that the mathematical expectancy of the DC decreases as a function of the number of interactions. This effect vanishes as the parameter values $\pi_{i j}$ approach 1 . Regarding group size, it does not affect to the mathematical expectancy of the estimator under any assumed parameter values (see Figures $1 \mathrm{a}$ and $1 \mathrm{~b}$ ). In fact, the bias of the estimator increases as the number of behaviours decreases and the parameters $\pi_{i j}$ approach to .5 (see below for computing the bias).

INSERT FIGURE 1 ABOUT HERE 
Of special interest may be the particular case in which $\pi_{\mathrm{ij}}=\pi_{\mathrm{ji}}=1 / 2$ for every dyad, since this corresponds to complete reciprocation among individuals. In this case the probability for each possible value of $\left|\mathrm{x}_{\mathrm{ij}}-\mathrm{x}_{\mathrm{ji}}\right|$ can be expressed in the following way:

$$
\begin{aligned}
& \operatorname{Pr}\left\{\left|x_{i j}-x_{j i}\right|=c_{i j}\right\}=2\left(\frac{1}{2}\right)^{c_{i j}}=\frac{1}{2^{c_{i j}-1}} . \\
& \operatorname{Pr}\left\{\left|x_{i j}-x_{j i}\right|=c_{i j}-2\right\}=\left(\begin{array}{c}
c_{i j} \\
c_{i j}-1
\end{array}\right) 2\left(\frac{1}{2}\right)^{c_{i j}}=\frac{c_{i j}}{2^{c_{i j}-1}} . \\
& \operatorname{Pr}\left\{\left|x_{i j}-x_{j i}\right|=c_{i j}-4\right\}=\left(\begin{array}{c}
c_{i j} \\
c_{i j}-2
\end{array}\right) 2\left(\frac{1}{2}\right)^{c_{i j}}=\frac{c_{i j}\left(c_{i j}-1\right)}{2 ! 2^{c_{i j}-1}} . \\
& \vdots \\
& \operatorname{Pr}\left\{\left|x_{i j}-x_{j i}\right|=c_{i j}-2 m_{i j}\right\}=\left(\begin{array}{c}
c_{i j} \\
c_{i j}-m_{i j}
\end{array}\right) 2\left(\frac{1}{2}\right)^{c_{i j}}=\frac{c_{i j}\left(c_{i j}-1\right) \cdots\left(c_{i j}-m_{i j}+1\right)}{m_{i j} ! 2^{c_{i j}-1}} .
\end{aligned}
$$

Now the mathematical expectancy of the DC estimator under the null hypothesis of complete reciprocation can be computed, that is, $\pi_{\mathrm{ij}}=\pi_{\mathrm{ji}}=1 / 2$ for all dyads. First, the expected value of $\mathrm{E}\left[\left|\mathrm{x}_{\mathrm{ij}}-\mathrm{x}_{\mathrm{ji}}\right|\right]$ is computed as follows:

$$
\begin{aligned}
E\left[\left|x_{i j}-x_{j i}\right|\right] & =\frac{c_{i j}}{2^{c_{i j}-1}}+\sum_{k=1}^{m_{i j}} \operatorname{Pr}\left\{\left|x_{i j}-x_{j i}\right|=c_{i j}-2 k\right\}\left(c_{i j}-2 k\right) \\
& =\frac{c_{i j}}{2^{c_{j i}-1}}+\sum_{k=1}^{m_{i j}} \frac{c_{i j} \cdots\left(c_{i j}-k+1\right)}{k ! 2^{c_{i j}-1}}\left(c_{i j}-2 k\right) \\
& =\frac{c_{i j}}{2^{c_{i j}-1}}+\frac{1}{2^{c_{i j}-1}} \sum_{k=1}^{m_{i j}} \frac{c_{i j} \cdots\left(c_{i j}-k+1\right)}{k !}\left(c_{i j}-2 k\right) \\
& =\frac{1}{2^{c_{i j}-1}}\left(c_{i j}+\sum_{k=1}^{m_{i j}} \frac{c_{i j} \cdots\left(c_{i j}-k+1\right)}{k !}\left(c_{i j}-2 k\right)\right) .
\end{aligned}
$$

Thus, 


$$
E[D C]=\frac{1}{N} \sum_{i=1}^{n} \sum_{j=i+1}^{n}\left(\frac{1}{2^{c_{i j}-1}}\left(c_{i j}+\sum_{k=1}^{m_{i j}} \frac{c_{i j} \cdots\left(c_{i j}-k+1\right)}{k !}\left(c_{i j}-2 k\right)\right)\right) .
$$

Although interpreting DC values may seem straightforward enough it should be noted that the DC estimator is biased under the null hypothesis of complete reciprocation. Therefore, the statistic's values should be compared with its expected value instead of zero in order to take decisions regarding social reciprocity in groups.

The variance of the DC estimator equals (see Appendix I)

$$
\sigma^{2}(D C)=\frac{1}{N^{2}} \sum_{i=1}^{n} \sum_{j=i+1}^{n}\left(\sum_{k=0}^{p_{i j}} \operatorname{Pr}\left\{\left|x_{i j}-x_{j i}\right|=c_{i j}-2 k\right\}\left(c_{i j}-2 k-E\left[\left|x_{i j}-x_{j i}\right|\right]\right)^{2}\right),
$$

where $\mathrm{p}_{\mathrm{ij}}=\mathrm{m}_{\mathrm{ij}}$ if $c_{i j}$ is odd and $\mathrm{p}_{\mathrm{ij}}=\mathrm{m}_{\mathrm{ij}}+1$ if $c_{i j}$ is even. The variance increases or decreases as a function of $\pi_{i j}$ and $c_{i j}$ (see Figure 2). When increasing the number of behaviours per dyad, the variability of the directional consistency estimator approaches gradually 0 . Additionally, it can be noted that its variability increases when moderate conditions of social reciprocity are assumed (i.e., $\pi_{i j}$ is approximately equal to .7). Furthermore the variance of the directional consistency estimator decreases as group size increases (Figures 2a and 2b).

\section{INSERT FIGURE 2 ABOUT HERE}

If $\pi_{\mathrm{ij}}=1 / 2$ for all dyads and $c_{i j}$ is odd, then 


$$
\begin{aligned}
E\left[\left(\left|x_{i j}-x_{j i}\right|-E\left[\left|x_{i j}-x_{j i}\right|\right]\right)^{2}\right]=\sum_{k=0}^{m_{i j}} \operatorname{Pr}\left\{\left|x_{i j}-x_{j i}\right|=c_{i j}-2 k\right\}\left(c_{i j}-2 k-E\left[\left|x_{i j}-x_{j i}\right|\right]\right)^{2} \\
=\frac{\left(c_{i j}-E\left[\left|x_{i j}-x_{j i}\right|\right]\right)^{2}}{2^{c_{i j}-1}}+\sum_{k=1}^{m_{i j}} \frac{c_{i j} \cdots\left(c_{i j}-k+1\right)}{k ! 2^{c_{i j}-1}}\left(c_{i j}-2 k-E\left[\left|x_{i j}-x_{j i}\right|\right]\right)^{2} \\
=\frac{\left(c_{i j}-E\left[\left|x_{i j}-x_{j i}\right|\right]\right)^{2}}{2^{c_{i j}-1}}+\frac{1}{2^{c_{i j}-1}} \sum_{k=1}^{m_{i j}} \frac{c_{i j} \cdots\left(c_{i j}-k+1\right)}{k !}\left(c_{i j}-2 k-E\left[\left|x_{i j}-x_{j i}\right|\right]\right)^{2} \\
=\frac{1}{2^{c_{i j}-1}}\left(\left(c_{i j}-E\left[\left|x_{i j}-x_{j i}\right|\right]\right)^{2}+\sum_{k=1}^{m_{i j}} \frac{c_{i j} \cdots\left(c_{i j}-k+1\right)}{k !}\left(c_{i j}-2 k-E\left[\left|x_{i j}-x_{j i}\right|\right]\right)^{2}\right) .
\end{aligned}
$$

Additionally, if $\pi_{\mathrm{ij}}=1 / 2$ for all dyads and $c_{i j}$ is even

$$
\begin{aligned}
E\left[\left(\left|x_{i j}-x_{j i}\right|-\right.\right. & \left.\left.E\left[\left|x_{i j}-x_{j i}\right|\right]\right)^{2}\right]=\sum_{k=0}^{m_{i j}+1} \operatorname{Pr}\left\{\left|x_{i j}-x_{j i}\right|=c_{i j}-2 k\right\}\left(c_{i j}-2 k-E\left[\left|x_{i j}-x_{j i}\right|\right]\right)^{2} \\
= & \frac{\left(c_{i j}-E\left[\left|x_{i j}-x_{j i}\right|\right]\right)^{2}}{2^{c_{i j}-1}}+\sum_{k=1}^{m_{i j}} \frac{c_{i j} \cdots\left(c_{i j}-k+1\right)}{k ! 2^{c_{i j}-1}}\left(c_{i j}-2 k-E\left[\left|x_{i j}-x_{j i}\right|\right]\right)^{2}+ \\
& \frac{c_{i j} \cdots\left(c_{i j} / 2+1\right) E^{2}\left[\left|x_{i j}-x_{j i}\right|\right]}{\left(c_{i j} / 2\right) ! 2^{c_{i j}}} \\
= & \frac{\left(c_{i j}-E\left[\left|x_{i j}-x_{j i}\right|\right]\right)^{2}}{2^{c_{i j}-1}}+\frac{1}{2^{c_{i j}-1}} \sum_{k=1}^{m_{i j}} \frac{c_{i j} \cdots\left(c_{i j}-k+1\right)}{k !}\left(c_{i j}-2 k-E\left[\left|x_{i j}-x_{j i}\right|\right]\right)^{2}+ \\
& \frac{c_{i j} \cdots\left(c_{i j} / 2+1\right) E^{2}\left[\left|x_{i j}-x_{j i}\right|\right]}{\left(c_{i j} / 2\right) ! 2^{c_{i j}}} \\
& \frac{1}{2^{c_{i j}-1}\left(\left(c_{i j}-E\left[\left|x_{i j}-x_{j i}\right|\right]\right)^{2}+\sum_{k=1}^{m_{i j}} \frac{c_{i j} \cdots\left(c_{i j}-k+1\right)}{k !}\left(c_{i j}-2 k-E\left[\left|x_{i j}-x_{j i}\right|\right]\right)^{2}\right)+} \\
& \frac{c_{i j} \cdots\left(c_{i j} / 2+1\right) E^{2}\left[\left|x_{i j}-x_{j i}\right|\right]}{\left(c_{i j} / 2\right) ! 2^{c_{i j}}} .
\end{aligned}
$$

Now, using the proper expression in the formulae, one can compute the variance of the DC estimator and its standard error. 
The skew-symmetry index: Expected value and standard error

Here the expected value and standard error for the skew-symmetry estimator is obtained. Firstly, this statistic can be expressed as follows:

$$
\begin{aligned}
\hat{\Phi} & =\frac{\operatorname{tr}(\mathbf{K} \mathbf{K})}{\operatorname{tr}\left(\mathbf{X}^{\prime} \mathbf{X}\right)}=\frac{\sum_{i=1}^{n} \sum_{j=1}^{n}\left(\frac{x_{i j}-x_{j i}}{2}\right)^{2}}{\sum_{i=1}^{n} \sum_{j=1}^{n} x_{i j}^{2}}=\frac{\sum_{i=1}^{n} \sum_{j=1}^{n}\left(x_{i j}-x_{j i}\right)^{2}}{4 \sum_{i=1}^{n} \sum_{j=1}^{n} x_{i j}^{2}} \\
& =\frac{\sum_{i=1}^{n} \sum_{j=1}^{n} x_{i j}^{2}-2 \sum_{i=1}^{n} \sum_{j=1}^{n} x_{i j} x_{j i}+\sum_{i=1}^{n} \sum_{j=1}^{n} x_{j i}^{2}}{4 \sum_{i=1}^{n} \sum_{j=1}^{n} x_{i j}^{2}}=\frac{\sum_{i=1}^{n} \sum_{j=1}^{n} x_{i j}^{2}-\sum_{i=1}^{n} \sum_{j=1}^{n} x_{i j}\left(c_{i j}-x_{i j}\right)}{2 \sum_{i=1}^{n} \sum_{j=1}^{n} x_{i j}^{2}} \\
& =\frac{\sum_{i=1}^{n} \sum_{j=1}^{n} x_{i j}^{2}-\sum_{i=1}^{n} \sum_{j=1}^{n} c_{i j} x_{i j}+\sum_{i=1}^{n} \sum_{j=1}^{n} x_{i j}^{2}}{2 \sum_{i=1}^{n} \sum_{j=1}^{n} x_{i j}^{2}}=1-\frac{\sum_{i=1}^{n} \sum_{j=1}^{n} c_{i j} x_{i j}}{2 \sum_{i=1}^{n} \sum_{j=1}^{n} x_{i j}^{2}}=1-\frac{\sum_{i=1}^{n} \sum_{j=i+1}^{n} c_{i j}\left(x_{i j}+x_{j i}\right)}{2 \sum_{i=1}^{n} \sum_{j=1}^{n} x_{i j}^{2}} \\
& =1-\frac{\sum_{i=1}^{n} \sum_{j=i+1}^{n} c_{i j}^{2}}{2 \sum_{i=1}^{n} \sum_{j=1}^{n} x_{i j}^{2}}, \sum_{i=1}^{n} \sum_{j=1}^{n} x_{i j}^{2}>0 .
\end{aligned}
$$

It can be shown that the expected value for the skew-symmetry estimator is equal to (see Appendix II)

$$
E[\hat{\Phi}] \doteq 1-\frac{\sum_{i=1}^{n} \sum_{j=i+1}^{n} c_{i j}^{2}}{2 E\left[\sum_{i=1}^{n} \sum_{j=1}^{n} x_{i j}^{2}\right]}\left(1+\frac{\sum_{i=1}^{n} \sum_{j=i+1}^{n}\left(v_{i j}+2 s_{i j}\right)}{E^{2}\left[\sum_{i=1}^{n} \sum_{j=1}^{n} x_{i j}^{2}\right]}\right),
$$


where

$$
\begin{aligned}
v_{i j}+2 s_{i j}= & 4 c_{i j}\left(\pi_{i j}-7 \pi_{i j}^{2}+12 \pi_{i j}^{3}-6 \pi_{i j}^{4}\right)+8 c_{i j}^{2}\left(-\pi_{i j}+6 \pi_{i j}^{2}-10 \pi_{i j}^{3}+5 \pi_{i j}^{4}\right)+ \\
& 4 c_{i j}^{3}\left(\pi_{i j}-5 \pi_{i j}^{2}+8 \pi_{i j}^{3}-4 \pi_{i j}^{4}\right) .
\end{aligned}
$$

Figure 3 shows how the mathematical expectancy of the skew-symmetry estimator depends on $\pi_{i j}$ and $c_{i j}$. For complete and moderate reciprocity, the amount of behaviour in dyads has an effect on the mathematical expectancy of the skew-symmetry estimator. Thus, its mathematical expectancy decreases as the number of interactions increases. This effect disappears as parameters $\pi_{i j}$ are close to 1 . Similarly to the results obtained for the DC estimator, the mathematical expectancy of the skew-symmetry estimator seems to be unaffected by the group size (Figures $3 \mathrm{a}$ and $3 \mathrm{~b}$ ). Like the DC estimator, the bias of the skew-symmetry estimator increases as the number of behaviours decreases and the parameters $\pi_{i j}$ approach to .5 .

\section{INSERT FIGURE 3 ABOUT HERE}

If $\pi_{\mathrm{ij}}=.5$ for all $i$ and $j$, note that

$$
\begin{aligned}
E\left[\sum_{i=1}^{n} \sum_{j=1}^{n} x_{i j}^{2}\right] & =\sum_{i=1}^{n} \sum_{j=i+1}^{n} c_{i j}+\sum_{i=1}^{n} \sum_{j=1}^{n} c_{i j}^{2} \pi_{i j}^{2}-\sum_{i=1}^{n} \sum_{j=1}^{n} c_{i j} \pi_{i j}^{2} \\
& =\sum_{i=1}^{n} \sum_{j=i+1}^{n} c_{i j}+\frac{1}{4} \sum_{i=1}^{n} \sum_{j=1}^{n} c_{i j}^{2}-\frac{1}{4} \sum_{i=1}^{n} \sum_{j=1}^{n} c_{i j} \\
& =\sum_{i=1}^{n} \sum_{j=i+1}^{n} c_{i j}+\frac{1}{2} \sum_{i=1}^{n} \sum_{j=i+1}^{n} c_{i j}^{2}-\frac{1}{2} \sum_{i=1}^{n} \sum_{j=i+1}^{n} c_{i j} \\
& =\frac{1}{2}\left(\sum_{i=1}^{n} \sum_{j=i+1}^{n} c_{i j}^{2}+\sum_{i=1}^{n} \sum_{j=i+1}^{n} c_{i j}\right)
\end{aligned}
$$


and

$$
\begin{aligned}
v_{i j}+2 s_{i j}= & 4 c_{i j}\left(\pi_{i j}-7 \pi_{i j}^{2}+12 \pi_{i j}^{3}-6 \pi_{i j}^{4}\right)+8 c_{i j}^{2}\left(-\pi_{i j}+6 \pi_{i j}^{2}-10 \pi_{i j}^{3}+5 \pi_{i j}^{4}\right)+ \\
& 4 c_{i j}^{3}\left(\pi_{i j}-5 \pi_{i j}^{2}+8 \pi_{i j}^{3}-4 \pi_{i j}^{4}\right) \\
= & 4 c_{i j}\left(\frac{8-28+24-6}{16}\right)+8 c_{i j}^{2}\left(\frac{-8+24-20+5}{16}\right)+4 c_{i j}^{3}\left(\frac{8-20+16-4}{16}\right) \\
= & \frac{8 c_{i j}^{2}-8 c_{i j}}{16}=\frac{\left(c_{i j}^{2}-c_{i j}\right)}{2} .
\end{aligned}
$$

Then

$$
\begin{aligned}
E[\hat{\Phi}] \doteq 1-\frac{\sum_{i=1}^{n} \sum_{j=i+1}^{n} c_{i j}^{2}}{\sum_{i=1}^{n} \sum_{j=i+1}^{n} c_{i j}^{2}+\sum_{i=1}^{n} \sum_{j=i+1}^{n} c_{i j}}\left(1+\frac{2 \sum_{i=1}^{n} \sum_{j=i+1}^{n}\left(c_{i j}^{2}-c_{i j}\right)}{\left.\left(\sum_{i=1}^{n} \sum_{j=i+1}^{n} c_{i j}^{2}+\sum_{i=1}^{n} \sum_{j=i+1}^{n} c_{i j}\right)^{2}\right)}\right. \\
=1-\frac{\sum_{i=1}^{n} \sum_{j=i+1}^{n} c_{i j}^{2}}{\sum_{i=1}^{n} \sum_{j=i+1}^{n}\left(c_{i j}^{2}+c_{i j}\right)}\left(1+\frac{2 \sum_{i=1}^{n} \sum_{j=i+1}^{n}\left(c_{i j}^{2}-c_{i j}\right)}{\left(\sum_{i=1}^{n} \sum_{j=i+1}^{n}\left(c_{i j}^{2}+c_{i j}\right)\right)^{2}}\right) .
\end{aligned}
$$

Once again, note that the statistic's values should be compared with the expected values instead of zero when making statistical decisions regarding social reciprocity, as the skew-symmetry estimator is biased under the null hypothesis of complete reciprocation.

The general expression for computing the variance of the skew-symmetry estimator is (see Appendix II) 


$$
\begin{aligned}
\operatorname{Var}(\hat{\Phi}) \doteq \frac{\left(\sum_{i=1}^{n} \sum_{j=i+1}^{n} c_{i j}^{2}\right)^{2}}{4} \frac{1}{E^{2}\left[\sum_{i=1}^{n} \sum_{j=1}^{n} x_{i j}^{2}\right]}\left(\frac{\operatorname{Var}\left(\sum_{i=1}^{n} \sum_{j=1}^{n} x_{i j}^{2}\right)}{E^{2}\left[\sum_{i=1}^{n} \sum_{j=1}^{n} x_{i j}^{2}\right]}-\frac{2 \operatorname{Cov}\left(1, \sum_{i=1}^{n} \sum_{j=1}^{n} x_{i j}^{2}\right)}{E\left[\sum_{i=1}^{n} \sum_{j=1}^{n} x_{i j}^{2}\right]}\right) \\
=\frac{\left(\sum_{i=1}^{n} \sum_{j=i+1}^{n} c_{i j}^{2}\right)^{2}}{4 E^{2}\left[\sum_{i=1}^{n} \sum_{j=1}^{n} x_{i j}^{2}\right]} \frac{\operatorname{Var}\left(\sum_{i=1}^{n} \sum_{j=1}^{n} x_{i j}^{2}\right)}{E^{2}\left[\sum_{i=1}^{n} \sum_{j=1}^{n} x_{i j}^{2}\right]}=\frac{\left(\sum_{i=1}^{n} \sum_{j=i+1}^{n} c_{i j}^{2}\right)^{2} \sum_{i=1}^{n} \sum_{j=i+1}^{n}\left(v_{i j}+2 s_{i j}\right)}{4 E^{4}\left[\sum_{i=1}^{n} \sum_{j=1}^{n} x_{i j}^{2}\right]}
\end{aligned}
$$

Figure 4 shows how the variance of the skew-symmetry estimator varies for several values of $\pi_{i j}$ and $c_{i j}$. As it was found for the directional consistency estimator, the skewsymmetry estimator shows more variability in moderate conditions of social reciprocity, that is, for $\pi_{i j}$ values near .7. Note that its variability decreases as a function of the number of behaviours per dyad and the group size (Figures $4 \mathrm{a}$ and $4 \mathrm{~b}$ ).

\section{INSERT FIGURE 4 ABOUT HERE}

The variance of the skew-symmetry estimator, if $\pi_{\mathrm{ij}}=.5$ for all $i$ and $j$, equals

$$
\begin{aligned}
\operatorname{Var}(\hat{\Phi}) \doteq \frac{\left(\sum_{i=1}^{n} \sum_{j=i+1}^{n} c_{i j}^{2}\right)^{2} \sum_{i=1}^{n} \sum_{j=i+1}^{n}\left(v_{i j}+2 s_{i j}\right)}{4 E^{4}\left[\sum_{i=1}^{n} \sum_{j=1}^{n} x_{i j}^{2}\right]}=\frac{\left(\sum_{i=1}^{n} \sum_{j=i+1}^{n} c_{i j}^{2}\right)^{2} \sum_{i=1}^{n} \sum_{j=i+1}^{n} \frac{\left(c_{i j}^{2}-c_{i j}\right)}{2}}{4\left(\frac{1}{2}\left(\sum_{i=1}^{n} \sum_{j=i+1}^{n} c_{i j}^{2}+\sum_{i=1}^{n} \sum_{j=i+1}^{n} c_{i j}\right)\right)^{4}} \\
=\frac{2\left(\sum_{i=1}^{n} \sum_{j=i+1}^{n} c_{i j}^{2}\right)^{2} \sum_{i=1}^{n} \sum_{j=i+1}^{n}\left(c_{i j}^{2}-c_{i j}\right)}{\left(\sum_{i=1}^{n} \sum_{j=i+1}^{n} c_{i j}^{2}+\sum_{i=1}^{n} \sum_{j=i+1}^{n} c_{i j}\right)^{4}} .
\end{aligned}
$$


Now the standard error can be easily obtained.

\section{Mean square error for the DC and skew-symmetry estimators}

The following matrix contains the parameters $\pi_{i j}$ :

$$
\boldsymbol{\Pi}=\left(\begin{array}{ccccc}
0 & \pi_{12} & \pi_{13} & \cdots & \pi_{1 n} \\
1-\pi_{12} & 0 & \pi_{23} & \cdots & \pi_{2 n} \\
1-\pi_{13} & 1-\pi_{23} & 0 & \cdots & \vdots \\
\vdots & \vdots & \vdots & \ddots & \vdots \\
1-\pi_{1 n} & 1-\pi_{2 n} & \cdots & \cdots & 0
\end{array}\right) .
$$

Then, the expected values of $x_{i j}$ can be obtained for all admissible null hypotheses of social reciprocity as follows:

$$
E\left[x_{i j}\right]=\pi_{i j} c_{i j} ; i, j=1,2, \ldots, n, i \neq j .
$$

The matrix of expected values will be denoted by $\mathbf{X}_{\mathbf{e}}$ :

$$
\mathbf{X}_{\mathrm{e}}=\left(\begin{array}{ccccc}
0 & E\left[x_{12}\right] & E\left[x_{13}\right] & \cdots & E\left[x_{1 n}\right] \\
E\left[x_{21}\right] & 0 & E\left[x_{23}\right] & \cdots & E\left[x_{2 n}\right] \\
E\left[x_{31}\right] & E\left[x_{32}\right] & 0 & \cdots & \vdots \\
\vdots & \vdots & \vdots & \ddots & \vdots \\
E\left[x_{n 1}\right] & E\left[x_{n 2}\right] & \cdots & \cdots & 0
\end{array}\right),
$$

therefore, the value of the $\mathrm{DC}$ in the population $\left(\mathrm{DC}_{\mathrm{p}}\right)$ can be obtained as it is shown in the following expression: 


$$
D C_{p}=\frac{\sum_{i=1}^{n} \sum_{j=i+1}^{n}\left|2 E\left[x_{i j}\right]-c_{i j}\right|}{N}=\frac{\sum_{i=1}^{n} \sum_{j=i+1}^{n} c_{i j}\left|2 \pi_{i j}-1\right|}{N}, N=\sum_{i=1}^{n} \sum_{j=i+1}^{n} c_{i j} .
$$

Now, we can compute the mean square error $(M S E)$ for the directional consistency estimator as follows:

$$
\operatorname{MSE}(D C)=E^{2}\left[D C-D C_{p}\right]+\sigma^{2}(D C)=\operatorname{Bias}^{2}(D C)+\sigma^{2}(D C) .
$$

The MSE for the directional estimator decreases as a function of increasing the amount of behaviour in dyads and the parameter values $\pi_{i j}$ (see Figure 5).

\section{INSERT FIGURE 5 ABOUT HERE}

Regarding the skew-symmetry estimator, the matrix $\mathbf{K}_{\mathbf{e}}$ of expected skewsymmetrical values can be computed by means of the matrix $\mathbf{X}_{\mathbf{e}}$ :

$$
\mathbf{K}_{\mathrm{e}}=\frac{\mathbf{X}_{\mathrm{e}}-\mathbf{X}_{\mathrm{e}}^{\prime}}{2}
$$

Hence, the value of the skew-symmetry parameter equals

$$
\Phi=\frac{\sum_{i=1}^{n} \sum_{j=1}^{n} k_{e_{i j}}^{2}}{\sum_{i=1}^{n} \sum_{j=1}^{n} x_{e_{i j}}^{2}}=\frac{\sum_{i=1}^{n} \sum_{j=1}^{n}\left(\frac{E\left[x_{i j}\right]-E\left[x_{j i}\right]}{2}\right)^{2}}{\sum_{i=1}^{n} \sum_{j=1}^{n} \pi_{i j}^{2} c_{i j}^{2}}=\frac{\sum_{i=1}^{n} \sum_{j=1}^{n} c_{i j}^{2}\left(2 \pi_{i j}-1\right)^{2}}{4 \sum_{i=1}^{n} \sum_{j=1}^{n} \pi_{i j}^{2} c_{i j}^{2}} .
$$


Finally, the MSE for the skew-symmetry estimator is equal to

$$
\operatorname{MSE}(\hat{\Phi})=E^{2}[\hat{\Phi}-\Phi]+\sigma^{2}(\hat{\Phi})=\operatorname{Bias}^{2}(\hat{\Phi})+\sigma^{2}(\hat{\Phi})
$$

Figure 6 shows how the mean square error for the skew-symmetry estimator varies for several frequencies of dyadic interactions and parameter values $\pi_{i j}$. Similarly to the results obtained for the DC estimator, the MSE for the skew-symmetry estimator decreases when increasing $c_{i j}$ and $\pi_{i j}$.

\section{INSERT FIGURE 6 ABOUT HERE}

\section{An example}

The example consists of a sociomatrix taken from Vervaecke et al. (1999), in which dyadic encounters in a group of six captive primates are studied. This sociomatrix was originally used for sorting individuals into competitive rank orders in a feeding context. These social interaction data are here used in order to illustrate the computation of the mathematical expectancy and standard error for both the DC and skew-symmetry estimators. $\mathrm{R}$ functions have been developed in order to compute expected values, standard errors, and biases under specific null hypotheses; interested researchers can obtain these functions on request. Table 1 shows the sociomatrix containing the feeding scores, that is, each cell $x_{i j}$ represents the number of times that the $i$ th individual takes food in the presence of the $j$ th individual. 


\section{INSERT TABLE 1 ABOUT HERE}

Computing expected values and variances for the DC and skew-symmetry estimators allows researchers to obtain proper information regarding social reciprocity in groups, since it enables them to make suitable comparisons of empirical and theoretical values. The results from the group-level analysis of the six captive primates provide social researchers with some evidence of the non-reciprocal style in these social interactions. The empirical value of the DC statistic was found to be extremely different from its expected value under the hypothesis of complete reciprocation $(\mathrm{DC}=0.630667$ and $\left.E[D C]=0.079589 ; \sigma^{2}[D C]=0.000244\right)$. Similar results were found when the analysis was performed for the skew-symmetry statistic $(\Phi=0.328089$ and $\mathrm{E}[\Phi] \doteq$ $\left.0.009882 ; \sigma^{2}[\Phi] \doteq 0.000013\right)$.

Given that expected values for both statistics under the hypothesis of complete reciprocity are almost equal to 0 and actual statistic values are far from their expected values, social researchers thus have some evidence regarding the non-reciprocal pattern in dyadic feeding behaviour observed in the group of captive primates.

Although this analysis enables social researchers to quantify overall reciprocity in the group, individual and dyadic effect can be also estimated in the example shown above. Regarding this issue, researchers can be interested in knowing whether the overall effect is mainly explained by the behaviour of a sole individual or a dyad, and not by the whole group pattern. Therefore, it can be useful to carry out the dyadic and individual decompositions for the skew-symmetry measurement (Solanas et al., 2006). 
Looking at the individual contributions to the skew-symmetry, it can be noted that all individuals in the group show asymmetrical relationships, being Dzeeta and Desmond the most asymmetrical individuals in the group $\left(v_{\mathrm{j}}=0.417\right.$ and $v_{\mathrm{j}}=0.375$, respectively). When decomposing $v_{j}$ into dyadic contributions, no differences were found in the dyadic decomposition of the skew-symmetry for the 15 dyads. Hence, there exists a skew-symmetrical pattern in the overall functioning of the group, but this pattern is not explained by any specific dyadic relationship. In other words, all individuals were skew-symmetrical in their interactions regardless of the partner.

Despite we have illustrated the mathematical expressions for both the DC and the skew-symmetry estimators under the null hypothesis of complete reciprocation, different patterns can be specified in the null hypothesis. For instance, suppose that in feeding agonistic contexts the interactions among individuals are properly described by high degrees of asymmetry. Under this assumption researchers may be interested in testing the following null hypothesis:

$$
H o: \Pi=\left(\begin{array}{cccccc}
0 & .85 & .85 & .85 & .85 & .85 \\
.15 & 0 & .85 & .85 & .85 & .85 \\
.15 & .15 & 0 & .85 & .85 & .85 \\
.15 & .15 & .15 & 0 & .85 & .85 \\
.15 & .15 & .15 & .15 & 0 & .85 \\
.15 & .15 & .15 & .15 & .15 & 0
\end{array}\right)
$$

In this second example, all dyadic relationships are assumed to be extremely asymmetrical in the population. The empirical value of the DC statistic was found to be quite similar to its expected value under the hypothesis shown above $(\mathrm{DC}=0.630667$ and $\left.E[D C]=0.70 ; \sigma^{2}[D C]=0.00034\right)$. Similar results were found when the analysis 
was performed for the skew-symmetry statistic $\left(\Phi=0.328089\right.$ and $\mathrm{E}[\Phi] \doteq 0.331 ; \sigma^{2}[\Phi]$

$\doteq 0.00013$ ). Given these results, researchers have some evidence in favour of this more realistic pattern expressed in the null hypothesis. In other words, this could be a better model for describing dyadic agonistic encounters in a feeding context.

\section{Discussion}

This study provides some exact and approximate mathematical expressions for the bias and standard error of the DC and skew-symmetry estimators. Both measures are useful for quantifying social reciprocity and are based on dyadic discrepancies. The DC index allows social researchers to quantify social reciprocity at global level whereas the technique proposed by Solanas et al. (2006) allows researchers to decompose social reciprocity into different effects since individual, dyadic and group measurements can be obtained. Additionally, the statistical procedure also enables obtaining dyadic and generalized social reciprocity measures.

These expressions require social researchers to state the specific null hypothesis, and by comparing statistics and expected values it is possible to extract correct information about social reciprocity in groups. Thus, the expressions for bias will allow social researchers to make appropriate comparisons and develop proper descriptions. Standard error expressions will enable making decisions about the relative distance between the statistic values and the expected values under the assumed null hypothesis. In order to derive the mathematical expressions three assumptions have been made. Firstly, it has been supposed that the probability of the event "individual $i$ addresses behaviour to 
individual $j "\left(p_{i j}\right)$ is a constant value for every trial during the observation period. Given that the statistical methods being analysed are concerned with sociomatrices in which data are usually aggregated, despite being gathered in several observation sessions, it is necessary to make this assumption for a null hypothesis to be tested. In fact, a related assumption is implicit, for instance, in the SRM (Bond \& Lashley, 1996; Kenny \& La Voie, 1984; Warner et al., 1979). Specifically, the parameter value, the values of variances and covariances, must be supposed to be constant during the observation time in the SRM. Other techniques for analysing sociomatrices require this assumption, such as procedures for quantifying social dominance (Appleby, 1983; Boyd \& Silk, 1983; Tufto et al., 1998). This assumption appears to be realistic for modelling dyadic data if the period of observation is short enough. Therefore, researchers should establish periods of observation as short as possible if the studied procedures are to be used. Secondly, it is also assumed that the outcomes of the successive encounters are independent during the period of observation. This is a more restrictive assumption than the previous one since individuals may adapt their behaviour to the preceding results in the encounters. It should be noted again that the analysed techniques are concerned with aggregated data, which does not allow analysing interdependence. Although the presented statistical methods require sequential sociomatrices to analyse dependency, many researches deal with aggregated data in sociomatrices. In some studies, researchers have to aggregate data due to the scarce number of dyadic interactions in isolated sociomatrices, for instance, those obtained by an only observation session. The present study is focused on this kind of observational study and that is why it deals with aggregated sociomatrices, which do not allow estimating dependency between successive encounters. This seems to be a general problem, even if the SRM is carried out (Kenny, Kashy, \& Cook, 2006, pp. 217). Thirdly, it is additionally assumed that 
dyads' behaviours are independent. The reason is the same as explained above. It is reasonable to think that the second and third assumptions are invalid for many social studies. However, this third assumption is, for example, also assumed in the SRM (Kenny et al., 2006, pp. 216; Kenny \& La Voie, 1984; Warner, Kenny, \& Stoto, 1979). For the reasons mentioned above we only propose to use the studied statistical methods in those cases in which all three assumptions could be assumed or, at least, could approximately represent reality. The main problem with these assumptions or part of them is that many statistical methods, if applied to sociomatrices, also require the same suppositions, as it occurs when applying the binomial distribution.

Although the null hypothesis of complete reciprocation may be of interest for social researchers, other hypotheses can be specified since the statistical procedure allows specifying all admissible $\pi_{i j}$ values. For instance, social researchers who are interested in testing the maximum degree of asymmetry hypothesis in social interactions (e.g., hierarchy, directionality) must specify $\pi_{\mathrm{ij}}=1$ and $\pi_{\mathrm{ji}}=0$ for each dyad. Furthermore, the procedure allows social researchers to obtain bias and standard error for the DC and skew-symmetry estimators under all social reciprocity null hypotheses. Note that researchers could specify more complex patterns of dyadic interactions since the statistical procedure allows it (for instance, $\pi_{12}=0.4, \pi_{21}=0.6, \pi_{13}=0.2, \pi_{31}=0.8$, and so on). The mathematical expressions here presented can be applied to all null hypotheses concerning social reciprocity. The specific null hypothesis must be chosen by researchers in accordance with theoretical basis and research objectives.

Round-robin designs require intensive data gathering, therefore this kind of design are not common in social psychology research (Kenny et al., 2006). Regarding this 
issue, it should be highlighted that the mathematical expressions here presented can be also applied to other reciprocal designs, such as standard and block designs. The mathematical expressions work well in those cases in which there are dyads with no interaction, that is, $\mathrm{c}_{\mathrm{ij}}=0$. Hence, social researchers can obtain bias and standard error values for the DC and the skew-symmetry estimators just assigning $\pi_{\mathrm{ij}}=\pi_{\mathrm{ji}}=0$ in the developed R functions. For example, social researchers will be able to obtain bias and standard error for both estimators in standard dyadic designs and thus measuring the degree of overall social reciprocity for the set of available dyads.

Future research is needed to determine the exact or approximate sampling distributions for the DC and skew-symmetry statistics, as well as, propose mathematical procedures that deal with non-dependence and do not suppose such restrictive assumptions as the technique here presented. Additionally, bias, standard error, and sampling distribution should be obtained for dyadic and individual effects.

\section{References}

Albright, L., Kenny, D. A., \& Malloy, T. E. (1988). Consensus in personality judgements at zero acquaintance. Journal of Personality and Social Psychology, 55, 387-395.

Appleby, M. C. (1983). The probability of linearity in hierarchies. Animal Behaviour, $31,600-608$.

Bond, C. F. Jr., \& Lashley, R. B. (1996). Round-robin analysis of social interaction: exact and estimated standard errors. Psychometrika, 61, 303-311. 
Boyd, R., \& Silk, J. B. (1983). A method for assigning cardinal dominance ranks. Animal Behaviour, 31, 45-58.

Côté, S. D. (2000). Determining social rank in ungulates: A comparison of aggressive interactions recorded at a bait site and under natural conditions. Ethology, 106, 945955.

Cook, W. L. (2005). The SRM approach to family assessment. An introduction and case example. European Journal of Psychological Assessment, 21, 216-225.

Cook, W. L., \& Kenny, D. A. (2004). Application of the Social Relations Model to Family Assessment. Journal of Family Psychology, 18, 361-371.

Delsing, M. J. M. H., Oud, J. H. L., De Bruyn, E. E. J., \& Van Aken, M. A. G. (2003). Current and recollected perceptions of family relationships: The Social Relations Model approach to members of three generations. Journal of Family Psychology, $17,445-459$.

Johnson, N. L., Kotz, S., \& Kemp, A. W. (1992). Univariate discrete distributions. New York: John Wiley \& Sons.

Kenny, D. A., \& De Paulo, B. M. (1993). Do people know how others view them? An empirical and theoretical account. Psychological Bulletin, 114, 145-161.

Kenny, D. A., Kashy, D. A., \& Cook, W. L. (2006). Dyadic data analysis. New York: Guilford Press.

Kenny, D. A., \& La Voie, L. J. (1984). The social relations model. In L. Berkovitz (Ed.), Advances in experimental psychology (Vol. 18, pp. 142-182). San Diego, CA: Academic Press.

Kenny, D. A., \& Nasby, W. (1980). Splitting the reciprocity correlation. Journal of Personality and Social Psychology, 38, 249-256. 
Koenig, A., Larney, E., Lu, A., \& Borries, K. (2004). Agonistic behavior and dominance relationships in female Phayre's leaf monkeys. American Journal of Primatology, 64, 351-357.

Landau, H. G. (1951). On dominance relations and the structure of animal societies: I. Effect of inherent characteristics. Bulletin of Mathematical Biophysics, 13, 1-19.

Lashley, R. B., \& Bond, C. F. Jr. (1997). Significance testing for round robin data. Psychological Methods, 2, 278-291.

Leiva, D., Solanas, A., \& Salafranca, L1. (2008). Testing reciprocity in social interactions: A comparison between the directional consistency and skew-symmetry statistics. Behavior Research Methods, 40, 626-634.

Malloy, T. E., \& Albright, L. (1990). Interpersonal perception in a social context. Journal of Personality and Social Psychology, 58, 419-428.

Malloy, T. E., \& Albright, L. (2001). Multiple and single interaction dyadic research designs: Conceptual and analytic issues. Basic and Applied Social Psychology, 23, $1-19$.

Miller, D.C., \& Byrnes, J.P. (1997). The role of contextual and personal factors in children's risk tasking. Developmental Psychology, 33, 814-823.

Pelletier, F., \& Festa-Bianchet, M. (2006). Sexual selection and social rank in bighorn rams. Animal Behaviour, 71, 649-655.

Solanas, A., Salafranca, Ll., Riba, C., Sierra, V., \& Leiva, D. (2006). Quantifying social asymmetric structures. Behavior Research Methods, 38, 390-399.

Stevens, J. M. G., Vervaecke, H., de Vries, H., \& van Elsacker, L. (2005). Peering is not a formal indicator of subordination in bonobos (Pan Paniscus). American Journal of Primatology, 65, 255-267. 
Stuart, A., \& Ord, J. K. (1994). Kendall's advanced theory of statistics. Volume 1. Distribution theory. New York: John Wiley \& Sons.

Tufto, J., Solberg, E. J., \& Ringsby, T. (1998). Statistical models of transitive and intransitive dominance structures. Animal Behaviour, 55, 1489-1498.

van Hooff, J. A. R. A. M., \& Wensing, J. A. B. (1987). Dominance and its behavioral measures in a captive wolf pack. In H. W. Frank (Ed.), Man and wolf (pp. 219-252). Dordrecht: Junk Publishers.

Vervaecke, H., de Vries, H., \& Van Elsacker, L. (1999). An experimental evaluation of the consistency of competitive ability and agonistic dominance in different social contexts in captive bonobos. Behaviour, 136, 423-442.

Vogel, E. R. (2005). Rank differences in energy intake rates in white-faced capuchin monkeys, Cebus capucinus: The effects of contest competition. Behavioral Ecology and Sociobiology, 58, 333-344.

Warner, R. M., Kenny, D. A., \& Stoto, M. (1979). A new round-robin analysis of variance for social interaction data. Journal of Personality and Social Psychology, $37,1742-1757$.

Whitley, B. E., Ward, J., \& Snyder, H. N. (1984). Peer preferences in a desegregated school: A round robin analysis. Journal of Personality and Social Psychology, 46, 799-810.

Wittemyer, G., \& Getz, W.M. (2007). Hierarchical dominance structure and social organization in African elephants, Loxodonta africana. Animal Behaviour, 63, 671681. 


\section{Appendix I}

Given the assumptions stated in the text, the probability values for $\left|\mathrm{x}_{\mathrm{ij}}-\mathrm{x}_{\mathrm{ji}}\right|$ can be solved as follows:

$$
\begin{aligned}
& \operatorname{Pr}\left\{\left|x_{i j}-x_{j i}\right|=c_{i j}\right\}=\left(\begin{array}{c}
c_{i j} \\
c_{i j}
\end{array}\right)\left(\pi_{i j}^{c_{i j}}\left(1-\pi_{i j}\right)^{0}+\pi_{i j}^{0}\left(1-\pi_{i j}\right)^{c_{i j}}\right)=\pi_{i j}^{c_{i j}}+\left(1-\pi_{i j}\right)^{c_{i j}} . \\
& \operatorname{Pr}\left\{\left|x_{i j}-x_{j i}\right|=c_{i j}-2\right\}=\left(\begin{array}{c}
c_{i j} \\
c_{i j}-1
\end{array}\right)\left(\pi_{i j}^{c_{i j}-1}\left(1-\pi_{i j}\right)^{1}+\pi_{i j}^{1}\left(1-\pi_{i j}\right)^{c_{i j}-1}\right) . \\
& \operatorname{Pr}\left\{\left|x_{i j}-x_{j i}\right|=c_{i j}-4\right\}=\left(\begin{array}{c}
c_{i j} \\
c_{i j}-2
\end{array}\right)\left(\pi_{i j}^{c_{i j}-2}\left(1-\pi_{i j}\right)^{2}+\pi_{i j}^{2}\left(1-\pi_{i j}\right)^{c_{i j}-2}\right) . \\
& \vdots \\
& \operatorname{Pr}\left\{\left|x_{i j}-x_{j i}\right|=c_{i j}-2 m_{i j}\right\}=\left(\begin{array}{c}
c_{i j} \\
c_{i j}-m_{i j}
\end{array}\right)\left(\pi_{i j}^{c_{i j}-m_{i j}}\left(1-\pi_{i j}\right)^{m_{i j}}+\pi_{i j}^{m_{i j}}\left(1-\pi_{i j}\right)^{c_{i j}-m_{i j}}\right), \\
& m_{i j}=\operatorname{int}\left[\frac{c_{i j}-1}{2}\right] \text { and } c_{i j}-2 m_{i j} \leq\left|x_{i j}-x_{j i}\right| \leq c_{i j} .
\end{aligned}
$$

It should be noted that $\operatorname{Pr}\left\{\left|\mathrm{x}_{\mathrm{ij}}-\mathrm{x}_{\mathrm{ji}}\right|=\mathrm{c}_{\mathrm{ij}} / 2\right\}$ for even $c_{i j}$ values has not been included as $\left|\mathrm{x}_{\mathrm{ij}}-\mathrm{x}_{\mathrm{ji}}\right|=0$ and its corresponding term thus vanishes when computing the expected value. Also note that the number of different values for $\left|x_{i j}-x_{j i}\right|$ equals $m_{i j}+2$, including $\left|\mathrm{x}_{\mathrm{ij}}-\mathrm{x}_{\mathrm{ji}}\right|=0$. Thus, the expected value for the DC estimator equals

$$
E[D C]=\frac{1}{N} \sum_{i=1}^{n} \sum_{j=i+1}^{n} E\left[\left|x_{i j}-x_{j i}\right|\right]=\frac{1}{N} \sum_{i=1}^{n} \sum_{j=i+1}^{n}\left(\sum_{k=0}^{m_{i j}} \operatorname{Pr}\left\{\left|x_{i j}-x_{j i}\right|=c_{i j}-2 k\right\}\left(c_{i j}-2 k\right)\right) .
$$

Having solved the expected value for the DC estimator, one can be interested in obtaining its standard error. Here it should be taken into account that if a random 
variable $X$ is binomially distributed, the random variable $X^{2}$ can also be described by a binomial probabilistic model. Thus, as it is assumed that dyadic outcomes are independent, the variance of the DC estimator is given by

$$
\begin{aligned}
\sigma^{2}(D C) & =\operatorname{Var}\left(\frac{\sum_{i=1}^{n} \sum_{j=i+1}^{n}\left|x_{i j}-x_{j i}\right|}{N}\right)=\frac{1}{N^{2}} \operatorname{Var}\left(\sum_{i=1}^{n} \sum_{j=i+1}^{n}\left|x_{i j}-x_{j i}\right|\right) \\
& =\frac{1}{N^{2}} \sum_{i=1}^{n} \sum_{j=i+1}^{n} \operatorname{Var}\left(\left|x_{i j}-x_{j i}\right|\right)=\frac{1}{N^{2}} \sum_{i=1}^{n} \sum_{j=i+1}^{n} E\left[\left(\left|x_{i j}-x_{j i}\right|-E\left[\left|x_{i j}-x_{j i}\right|\right]\right)^{2}\right] \\
& =\frac{1}{N^{2}} \sum_{i=1}^{n} \sum_{j=i+1}^{n}\left(\sum_{k=0}^{p_{i j}} \operatorname{Pr}\left\{\left|x_{i j}-x_{j i}\right|=c_{i j}-2 k\right\}\left(\left|x_{i j}-x_{j i}\right|-E\left[\left|x_{i j}-x_{j i}\right|\right]\right)^{2}\right) \\
& =\frac{1}{N^{2}} \sum_{i=1}^{n} \sum_{j=i+1}^{n}\left(\sum_{k=0}^{p_{i j}} \operatorname{Pr}\left\{\left|x_{i j}-x_{j i}\right|=c_{i j}-2 k\right\}\left(c_{i j}-2 k-E\left[\left|x_{i j}-x_{j i}\right|\right]\right)^{2}\right),
\end{aligned}
$$

where $\mathrm{p}_{\mathrm{ij}}=\mathrm{m}_{\mathrm{ij}}$ if $c_{i j}$ is odd and $\mathrm{p}_{\mathrm{ij}}=\mathrm{m}_{\mathrm{ij}}+1$ if $c_{i j}$ is even. 


\section{Appendix II}

The expected value of this estimator is equal to

$$
E[\hat{\Phi}]=1-E\left[\frac{\sum_{i=1}^{n} \sum_{j=i+1}^{n} c_{i j}^{2}}{2 \sum_{i=1}^{n} \sum_{j=1}^{n} x_{i j}^{2}}\right]=1-\frac{\sum_{i=1}^{n} \sum_{j=i+1}^{n} c_{i j}^{2}}{2} E\left[\frac{1}{\sum_{i=1}^{n} \sum_{j=1}^{n} x_{i j}^{2}}\right] .
$$

A precise enough approximation of the expected value for the quotient can be obtained by means of the delta method (Johnson, Kotz, \& Kemp, 1992; Stuart \& Ord, 1994), which is founded on Taylor's series expansion. Thus,

$$
\begin{aligned}
E\left[\frac{1}{\left.\sum_{i=1}^{n} \sum_{j=1}^{n} x_{i j}^{2}\right]}\right. & \doteq \frac{1}{E\left[\sum_{i=1}^{n} \sum_{j=1}^{n} x_{i j}^{2}\right]}\left(1+\frac{\operatorname{Var}\left(\sum_{i=1}^{n} \sum_{j=1}^{n} x_{i j}^{2}\right)}{E^{2}\left[\sum_{i=1}^{n} \sum_{j=1}^{n} x_{i j}^{2}\right]}-\frac{\operatorname{Cov}\left(1, \sum_{i=1}^{n} \sum_{j=1}^{n} x_{i j}^{2}\right)}{E\left[\sum_{i=1}^{n} \sum_{j=1}^{n} x_{i j}^{2}\right]}\right) \\
& =\frac{1}{E\left[\sum_{i=1}^{n} \sum_{j=1}^{n} x_{i j}^{2}\right]}\left(1+\frac{\operatorname{Var}\left(\sum_{i=1}^{n} \sum_{j=1}^{n} x_{i j}^{2}\right)}{E^{2}\left[\sum_{i=1}^{n} \sum_{j=1}^{n} x_{i j}^{2}\right]}\right) \\
& =\frac{E\left[\sum_{i=1}^{n} \sum_{j=1}^{n} x_{i j}^{2}\right]}{\sum_{i=1}^{n} \sum_{j=1}^{n} \operatorname{Var}\left(x_{i j}^{2}\right)+2 \sum_{i=1}^{n} \sum_{j=i+1}^{n} \operatorname{Cov}\left(x_{i j}^{2}, x_{j i}^{2}\right)} E^{2\left[\sum_{i=1}^{n} \sum_{j=1}^{n} x_{i j}^{2}\right]} .
\end{aligned}
$$

Then, 


$$
E[\hat{\Phi}]=1-E\left[\frac{\sum_{i=1}^{n} \sum_{j=i+1}^{n} c_{i j}^{2}}{2 \sum_{i=1}^{n} \sum_{j=1}^{n} x_{i j}^{2}}\right] \doteq 1-\frac{\sum_{i=1}^{n} \sum_{j=i+1}^{n} c_{i j}^{2}}{2 E\left[\sum_{i=1}^{n} \sum_{j=1}^{n} x_{i j}^{2}\right]}\left(1+\frac{\sum_{i=1}^{n} \sum_{j=1}^{n} \operatorname{Var}\left(x_{i j}^{2}\right)+2 \sum_{i=1}^{n} \sum_{j=i+1}^{n} \operatorname{Cov}\left(x_{i j}^{2}, x_{j i}^{2}\right)}{E^{2}\left[\sum_{i=1}^{n} \sum_{j=1}^{n} x_{i j}^{2}\right]}\right) .
$$

In order to compute the expected value of the estimator, the expected value, variances and covariances have to be solved in the previous expression. To solve these expressions note that the second, third and fourth moments about zero for a binomially distributed random variable are given by (Johnson, Kotz, \& Kemp, 1992, pp. 107)

$$
\begin{aligned}
& \mu_{2}^{\prime}=E\left[x_{i j}^{2}\right]=c_{i j} \pi_{i j}+c_{i j}\left(c_{i j}-1\right) \pi_{i j}^{2} . \\
& \mu_{3}^{\prime}=E\left[x_{i j}^{3}\right]=c_{i j} \pi_{i j}+3 c_{i j}\left(c_{i j}-1\right) \pi_{i j}^{2}+c_{i j}\left(c_{i j}-1\right)\left(c_{i j}-2\right) \pi_{i j}^{3} . \\
& \mu_{4}^{\prime}=E\left[x_{i j}^{4}\right]=c_{i j} \pi_{i j}+7 c_{i j}\left(c_{i j}-1\right) \pi_{i j}^{2}+6 c_{i j}\left(c_{i j}-1\right)\left(c_{i j}-2\right) \pi_{i j}^{3}+c_{i j}\left(c_{i j}-1\right)\left(c_{i j}-2\right)\left(c_{i j}-3\right) \pi_{i j}^{4} .
\end{aligned}
$$

Thus, the expected value can be solved as follows:

$$
\begin{aligned}
E\left[\sum_{i=1}^{n} \sum_{j=1}^{n} x_{i j}^{2}\right] & =\sum_{i=1}^{n} \sum_{j=1}^{n} E\left[x_{i j}^{2}\right]=\sum_{i=1}^{n} \sum_{j=1}^{n}\left(c_{i j} \pi_{i j}+c_{i j}\left(c_{i j}-1\right) \pi_{i j}^{2}\right)=\sum_{i=1}^{n} \sum_{j=1}^{n}\left(c_{i j} \pi_{i j}+c_{i j}^{2} \pi_{i j}^{2}-c_{i j} \pi_{i j}^{2}\right) \\
& =\sum_{i=1}^{n} \sum_{j=i+1}^{n} c_{i j}+\sum_{i=1}^{n} \sum_{j=1}^{n} c_{i j}^{2} \pi_{i j}^{2}-\sum_{i=1}^{n} \sum_{j=1}^{n} c_{i j} \pi_{i j}^{2} .
\end{aligned}
$$

Regarding the variances,

$$
\begin{aligned}
\operatorname{Var}\left(x_{i j}^{2}\right)=E\left[x_{i j}^{4}\right]-E^{2}\left[x_{i j}^{2}\right]= & c_{i j} \pi_{i j}+7 c_{i j}\left(c_{i j}-1\right) \pi_{i j}^{2}+6 c_{i j}\left(c_{i j}-1\right)\left(c_{i j}-2\right) \pi_{i j}^{3}+ \\
& c_{i j}\left(c_{i j}-1\right)\left(c_{i j}-2\right)\left(c_{i j}-3\right) \pi_{i j}^{4}-\left(c_{i j} \pi_{i j}+\left(c_{i j}^{2}-c_{i j}\right) \pi_{i j}^{2}\right)^{2} .
\end{aligned}
$$


After some algebraic operations,

$$
\begin{aligned}
\operatorname{Var}\left(x_{i j}^{2}\right)= & c_{i j} \pi_{i j}+7\left(c_{i j}^{2}-c_{i j}\right) \pi_{i j}^{2}+6\left(c_{i j}^{3}-3 c_{i j}^{2}+2 c_{i j}\right) \pi_{i j}^{3}+\left(c_{i j}^{4}-6 c_{i j}^{3}+11 c_{i j}^{2}-6 c_{i j}\right) \pi_{i j}^{4}- \\
& c_{i j}^{2} \pi_{i j}^{2}+2 c_{i j}^{2} \pi_{i j}^{3}-2 c_{i j}^{3} \pi_{i j}^{3}-c_{i j}^{2} \pi_{i j}^{4}+2 c_{i j}^{3} \pi_{i j}^{4}-c_{i j}^{4} \pi_{i j}^{4} \\
= & c_{i j} \pi_{i j}-7 c_{i j} \pi_{i j}^{2}+6 c_{i j}^{2} \pi_{i j}^{2}+12 c_{i j} \pi_{i j}^{3}-16 c_{i j}^{2} \pi_{i j}^{3}+4 c_{i j}^{3} \pi_{i j}^{3}-6 c_{i j} \pi_{i j}^{4}+10 c_{i j}^{2} \pi_{i j}^{4}-4 c_{i j}^{3} \pi_{i j}^{4} \\
= & c_{i j}\left(\pi_{i j}-7 \pi_{i j}^{2}+12 \pi_{i j}^{3}-6 \pi_{i j}^{4}\right)+c_{i j}^{2}\left(6 \pi_{i j}^{2}-16 \pi_{i j}^{3}+10 \pi_{i j}^{4}\right)+c_{i j}^{3}\left(4 \pi_{i j}^{3}-4 \pi_{i j}^{4}\right)=q_{i j} .
\end{aligned}
$$

It can now be shown that

$$
\begin{aligned}
\operatorname{Var}\left(x_{j i}^{2}\right)= & c_{i j}\left(\pi_{i j}-7 \pi_{i j}^{2}+12 \pi_{i j}^{3}-6 \pi_{i j}^{4}\right)+c_{i j}^{2}\left(-4 \pi_{i j}+18 \pi_{i j}^{2}-24 \pi_{i j}^{3}+10 \pi_{i j}^{4}\right)+ \\
& c_{i j}^{3}\left(4 \pi_{i j}-12 \pi_{i j}^{2}+12 \pi_{i j}^{3}-4 \pi_{i j}^{4}\right)=q_{j i} .
\end{aligned}
$$

Thus,

$$
\begin{gathered}
v_{i j}=q_{i j}+q_{j i}=2 c_{i j}\left(\pi_{i j}-7 \pi_{i j}^{2}+12 \pi_{i j}^{3}-6 \pi_{i j}^{4}\right)+c_{i j}^{2}\left(-4 \pi_{i j}+24 \pi_{i j}^{2}-40 \pi_{i j}^{3}+20 \pi_{i j}^{4}\right)+ \\
c_{i j}^{3}\left(4 \pi_{i j}-12 \pi_{i j}^{2}+16 \pi_{i j}^{3}-8 \pi_{i j}^{4}\right) .
\end{gathered}
$$

Now the expected value of the skew-symmetry estimator can be rewritten as follows

$$
E[\hat{\Phi}] \doteq 1-\frac{\sum_{i=1}^{n} \sum_{j=i+1}^{n} c_{i j}^{2}}{2 E\left[\sum_{i=1}^{n} \sum_{j=1}^{n} x_{i j}^{2}\right]}\left(1+\frac{\sum_{i=1}^{n} \sum_{j=i+1}^{n} v_{i j}+2 \sum_{i=1}^{n} \sum_{j=i+1}^{n} \operatorname{Cov}\left(x_{i j}^{2}, x_{j i}^{2}\right)}{E^{2}\left[\sum_{i=1}^{n} \sum_{j=1}^{n} x_{i j}^{2}\right]}\right) .
$$

Regarding the covariance terms, 


$$
\operatorname{Cov}\left(x_{i j}^{2}, x_{j i}^{2}\right)=E\left[\left(x_{i j}^{2}-E\left[x_{i j}^{2}\right]\right)\left(x_{j i}^{2}-E\left[x_{j i}^{2}\right]\right)\right]=E\left[x_{i j}^{2} x_{j i}^{2}\right]-E\left[x_{i j}^{2}\right] E\left[x_{j i}^{2}\right] .
$$

Given that,

$$
E\left[x_{i j}^{2} x_{j i}^{2}\right]=E\left[x_{i j}^{2}\left(c_{i j}-x_{i j}\right)^{2}\right]=c_{i j}^{2} E\left[x_{i j}^{2}\right]-2 c_{i j} E\left[x_{i j}^{3}\right]+E\left[x_{i j}^{4}\right]
$$

and

$$
E\left[x_{i j}^{2}\right] E\left[x_{j i}^{2}\right]=E\left[x_{i j}^{2}\right] E\left[\left(c_{i j}-x_{i j}\right)^{2}\right]=c_{i j}^{2} E\left[x_{i j}^{2}\right]-2 c_{i j} E\left[x_{i j}\right] E\left[x_{i j}^{2}\right]+E^{2}\left[x_{i j}^{2}\right],
$$

then

$$
\begin{aligned}
\operatorname{Cov}\left(x_{i j}^{2}, x_{j i}^{2}\right)= & E\left[x_{i j}^{4}\right]-2 c_{i j} E\left[x_{i j}^{3}\right]+2 c_{i j} E\left[x_{i j}\right] E\left[x_{i j}^{2}\right]-E^{2}\left[x_{i j}^{2}\right] \\
= & c_{i j}\left(\pi_{i j}-7 \pi_{i j}^{2}+12 \pi_{i j}^{3}-6 \pi_{i j}^{4}\right)+c_{i j}^{2}\left(-2 \pi_{i j}+12 \pi_{i j}^{2}-20 \pi_{i j}^{3}+10 \pi_{i j}^{4}\right)+ \\
& c_{i j}^{3}\left(-4 \pi_{i j}^{2}+8 \pi_{i j}^{3}-4 \pi_{i j}^{4}\right)=s_{i j}=s_{j i} .
\end{aligned}
$$

Thus,

$$
E[\hat{\Phi}] \doteq 1-\frac{\sum_{i=1}^{n} \sum_{j=i+1}^{n} c_{i j}^{2}}{2 E\left[\sum_{i=1}^{n} \sum_{j=1}^{n} x_{i j}^{2}\right]}\left(1+\frac{\sum_{i=1}^{n} \sum_{j=i+1}^{n}\left(v_{i j}+2 s_{i j}\right)}{E^{2}\left[\sum_{i=1}^{n} \sum_{j=1}^{n} x_{i j}^{2}\right]}\right) .
$$

Note that 


$$
\begin{aligned}
v_{i j}+2 s_{i j}= & 4 c_{i j}\left(\pi_{i j}-7 \pi_{i j}^{2}+12 \pi_{i j}^{3}-6 \pi_{i j}^{4}\right)+8 c_{i j}^{2}\left(-\pi_{i j}+6 \pi_{i j}^{2}-10 \pi_{i j}^{3}+5 \pi_{i j}^{4}\right)+ \\
& 4 c_{i j}^{3}\left(\pi_{i j}-5 \pi_{i j}^{2}+8 \pi_{i j}^{3}-4 \pi_{i j}^{4}\right) .
\end{aligned}
$$

Regarding the variance of the skew-symmetry estimator,

$$
\operatorname{Var}(\hat{\Phi})=\operatorname{Var}\left(\frac{\sum_{i=1}^{n} \sum_{j=i+1}^{n} c_{i j}^{2}}{2 \sum_{i=1}^{n} \sum_{j=1}^{n} x_{i j}^{2}}\right)=\frac{\left(\sum_{i=1}^{n} \sum_{j=i+1}^{n} c_{i j}^{2}\right)^{2}}{4} \operatorname{Var}\left(\frac{1}{\sum_{i=1}^{n} \sum_{j=1}^{n} x_{i j}^{2}}\right)
$$

and, according to the delta method,

$$
\begin{aligned}
\operatorname{Var}(\hat{\Phi}) \doteq \frac{\left(\sum_{i=1}^{n} \sum_{j=i+1}^{n} c_{i j}^{2}\right)^{2}}{4} \frac{1}{E^{2}\left[\sum_{i=1}^{n} \sum_{j=1}^{n} x_{i j}^{2}\right]}\left(\frac{\operatorname{Var}\left(\sum_{i=1}^{n} \sum_{j=1}^{n} x_{i j}^{2}\right)}{E^{2}\left[\sum_{i=1}^{n} \sum_{j=1}^{n} x_{i j}^{2}\right]}-\frac{2 \operatorname{Cov}\left(1, \sum_{i=1}^{n} \sum_{j=1}^{n} x_{i j}^{2}\right)}{E\left[\sum_{i=1}^{n} \sum_{j=1}^{n} x_{i j}^{2}\right]}\right) \\
=\frac{\left(\sum_{i=1}^{n} \sum_{j=i+1}^{n} c_{i j}^{2}\right)^{2}}{4 E^{2}\left[\sum_{i=1}^{n} \sum_{j=1}^{n} x_{i j}^{2}\right]} \frac{\operatorname{Var}\left(\sum_{i=1}^{n} \sum_{j=1}^{n} x_{i j}^{2}\right)}{E^{2}\left[\sum_{i=1}^{n} \sum_{j=1}^{n} x_{i j}^{2}\right]}=\frac{\left(\sum_{i=1}^{n} \sum_{j=i+1}^{n} c_{i j}^{2}\right)^{2} \sum_{i=1}^{n} \sum_{j=i+1}^{n}\left(v_{i j}+2 s_{i j}\right)}{4 E^{4}\left[\sum_{i=1}^{n} \sum_{j=1}^{n} x_{i j}^{2}\right]}
\end{aligned}
$$




\section{Tables}

Table 1. Dyadic feeding scores in a group of six captive bonobos (Vervaecke, de Vries \& van Elsacker, 1999; Brill Publishers. Printed with permission.)

\begin{tabular}{ccccccc}
\hline \multirow{2}{*}{ Actor } & \multicolumn{7}{c}{ Partner } \\
\cline { 2 - 7 } & Dzeeta & Hermien & Desmond & Kidogo & Hortense & Ludwig \\
\hline Dzeeta & - & 75 & 96 & 95 & 91 & 100 \\
Hermien & 25 & - & 73 & 89 & 64 & 94 \\
Desmond & 4 & 27 & - & 98 & 81 & 90 \\
Kidogo & 5 & 11 & 2 & - & 52 & 63 \\
Hortense & 9 & 36 & 19 & 48 & - & 62 \\
Ludwig & 0 & 6 & 10 & 37 & 38 & - \\
\hline
\end{tabular}




\section{Figure Captions}

Figure 1. Mathematical expectancy for the directional consistency estimator under several conditions of $\pi_{i j}$ and $c_{i j}$ for groups of $\mathrm{n}=4$ (1a) and $\mathrm{n}=6(1 \mathrm{~b})$.

Figure 2. Variance for the directional consistency estimator under several conditions of $\pi_{i j}$ and $c_{i j}$ for groups of $\mathrm{n}=4(2 \mathrm{a})$ and $\mathrm{n}=6(2 \mathrm{~b})$.

Figure 3. Mathematical expectancy for the skew-symmetry estimator under several conditions of $\pi_{i j}$ and $c_{i j}$ for groups of $\mathrm{n}=4(3 \mathrm{a})$ and $\mathrm{n}=6(3 \mathrm{~b})$.

Figure 4. Variance for the skew-symmetry estimator under several conditions of $\pi_{i j}$ and $c_{i j}$ for groups of $\mathrm{n}=4(4 \mathrm{a})$ and $\mathrm{n}=6(4 \mathrm{~b})$.

Figure 5. Mean square error for the directional consistency estimator under several conditions of $\pi_{i j}$ and $c_{i j}$ for groups of $\mathrm{n}=6$.

Figure 6. Mean square error for the skew-symmetry estimator under several conditions of $\pi_{i j}$ and $c_{i j}$ for groups of $\mathrm{n}=6$. 
Figure 1.

1a)

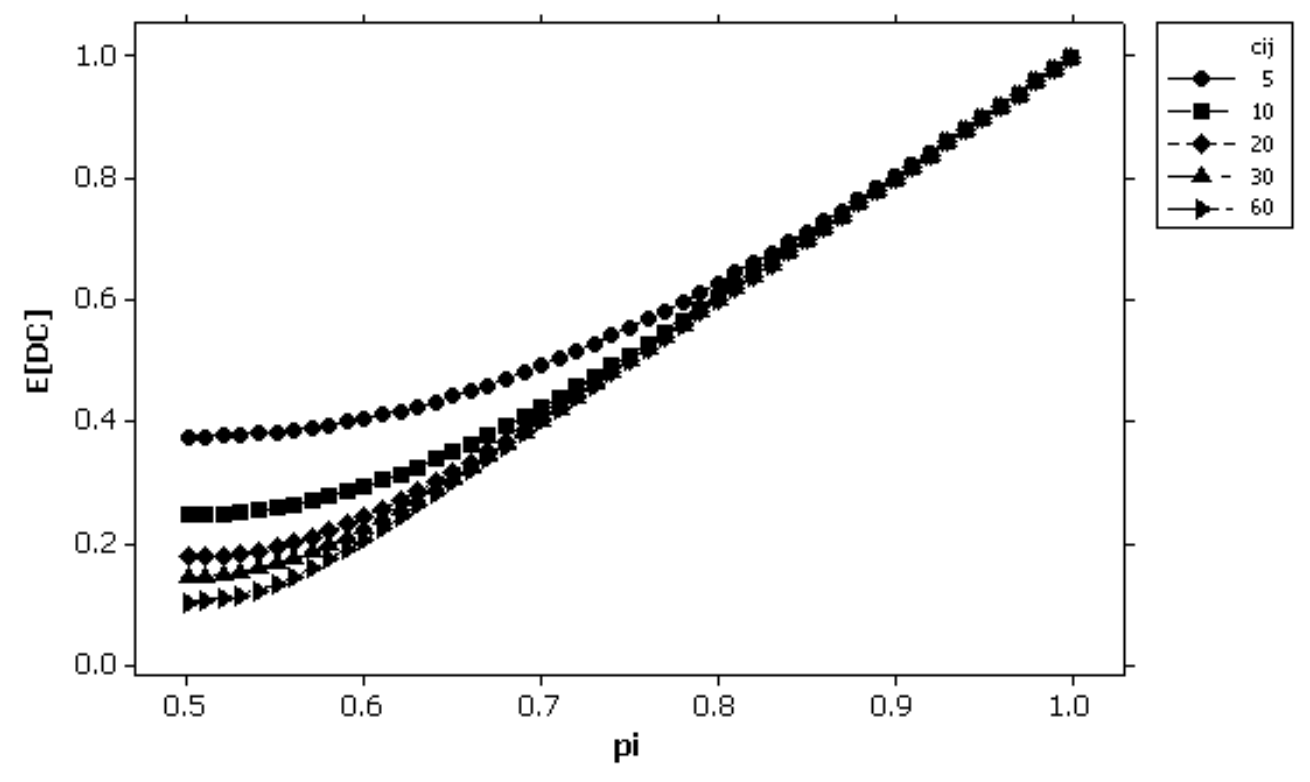

1b)

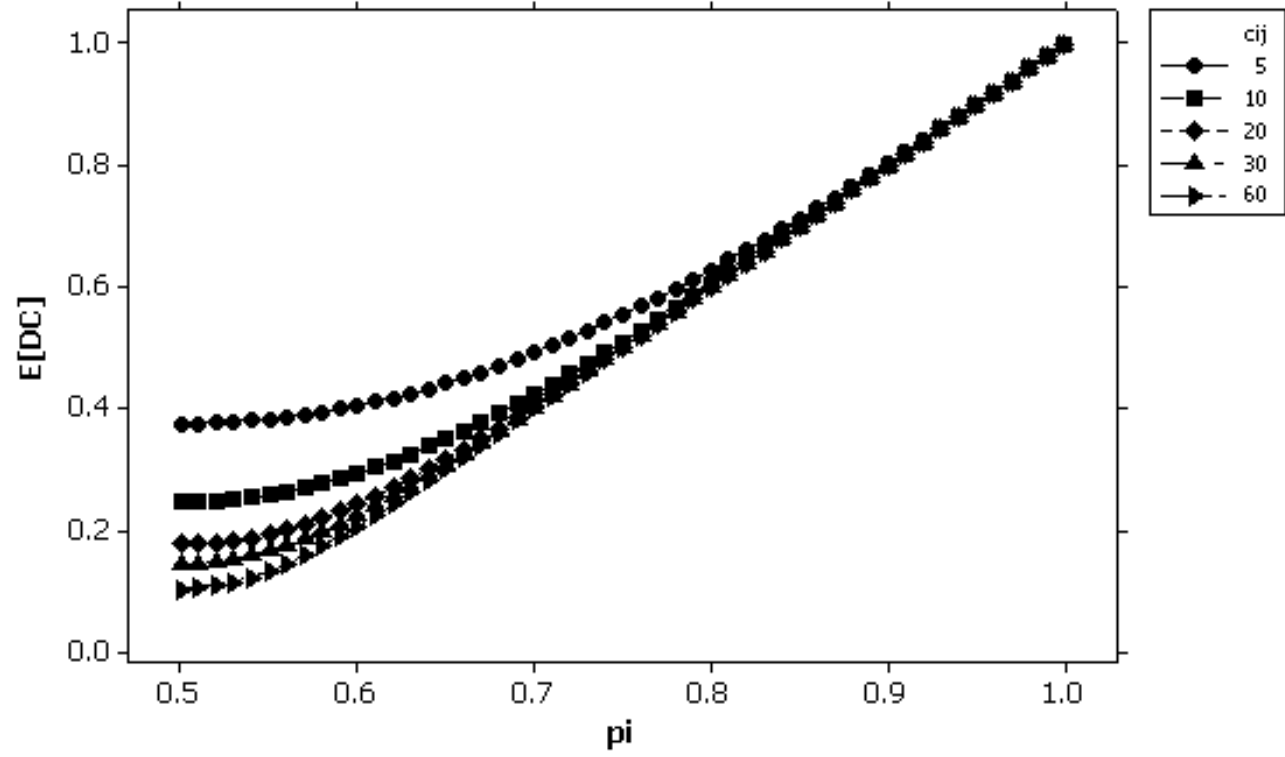


Figure 2.

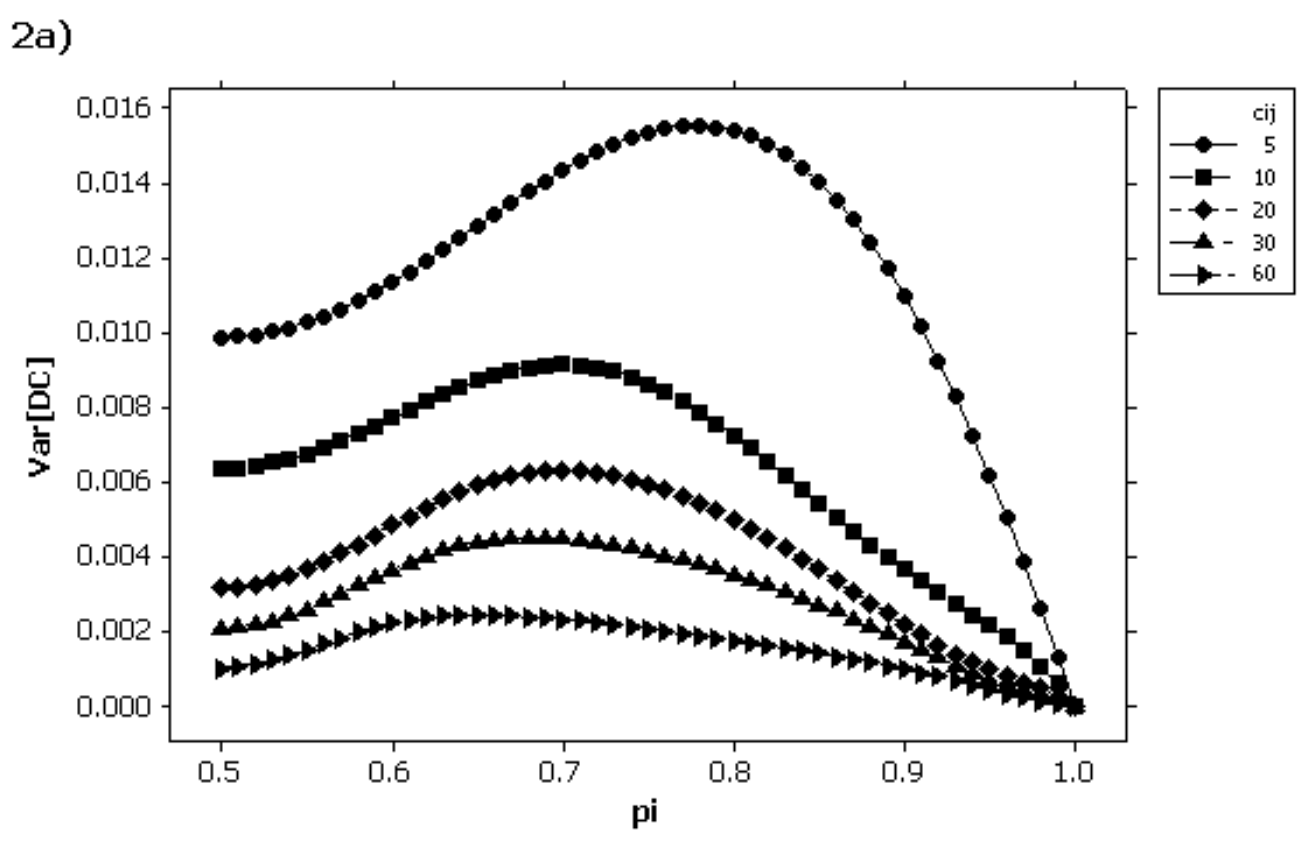

2b)

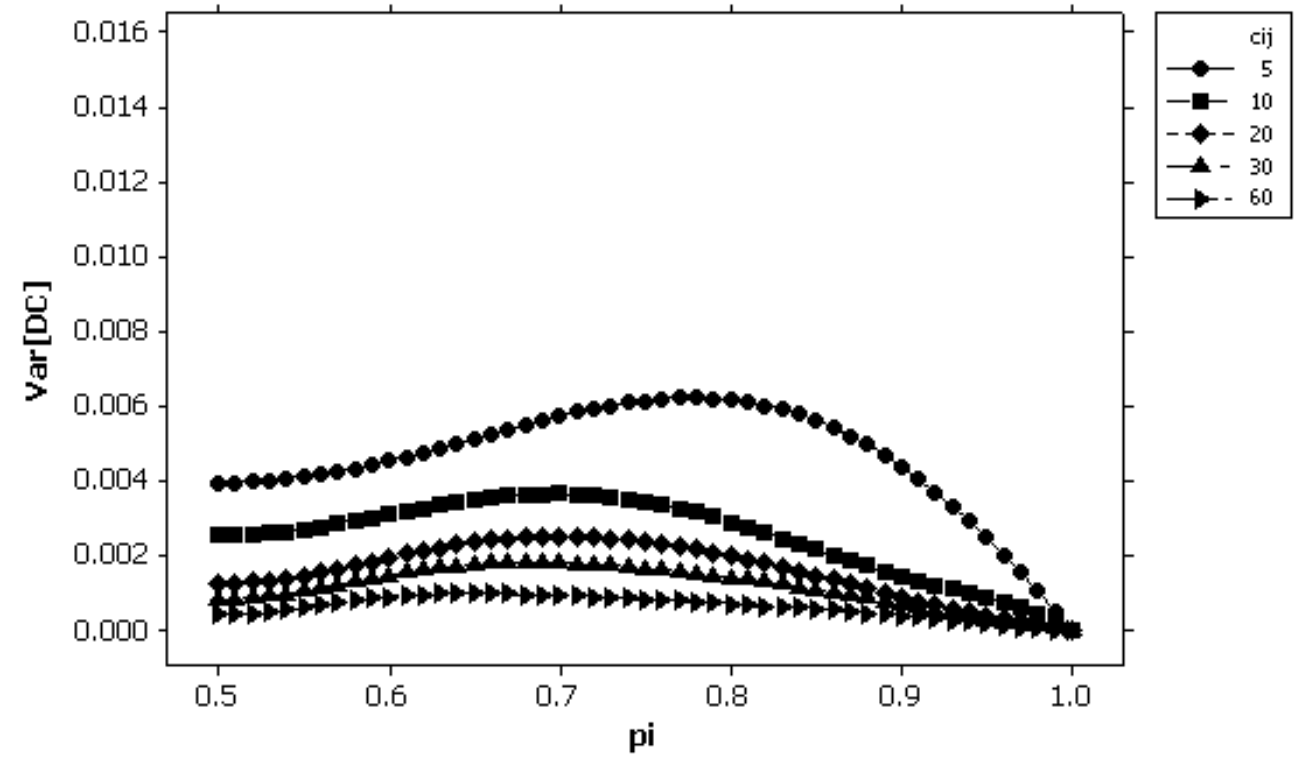


Figure 3.

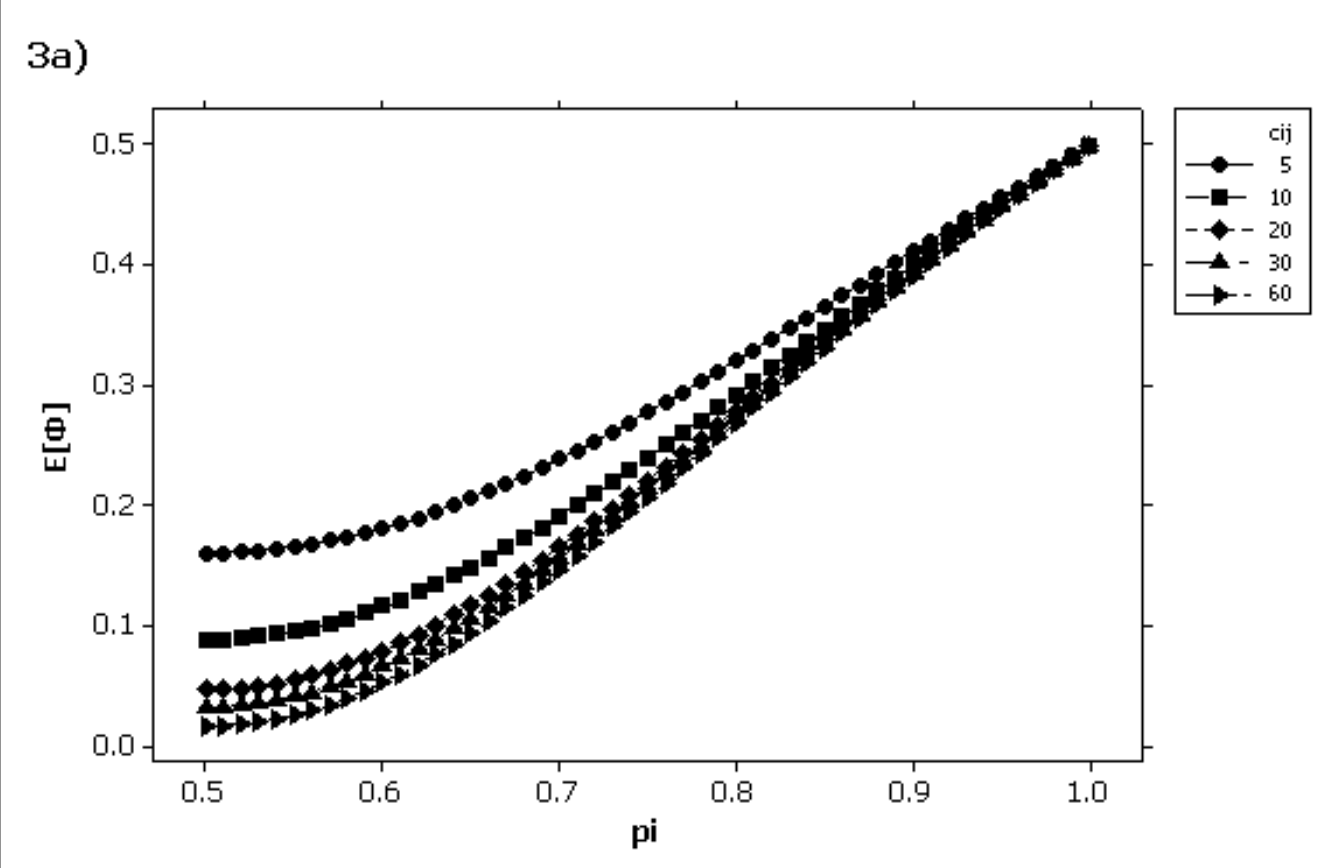

3b)

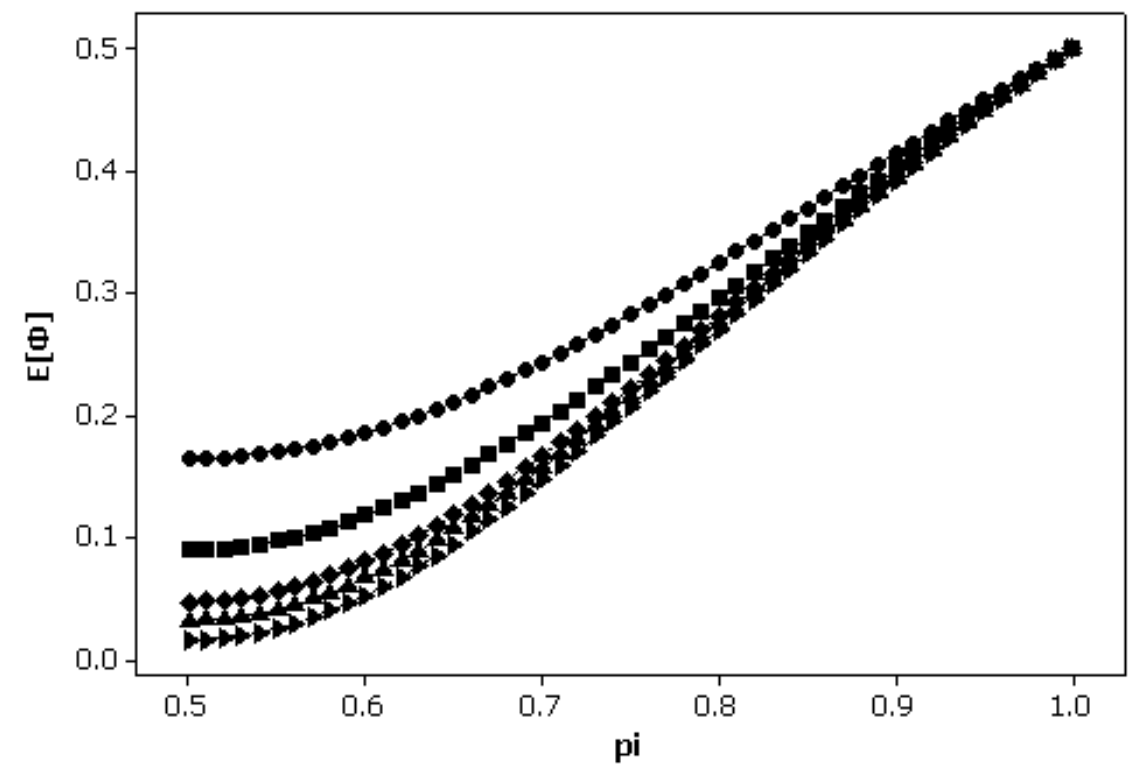


Figure 4.

4a)

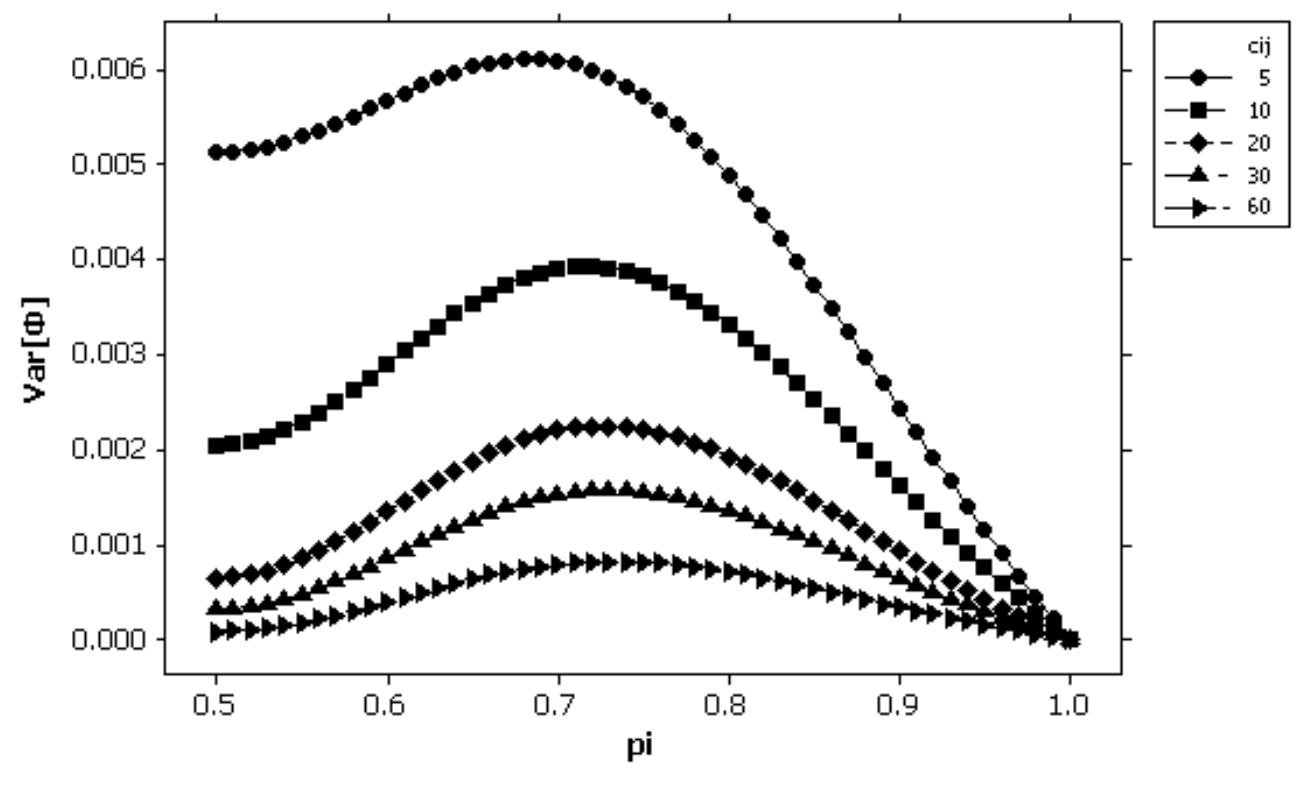

4b)

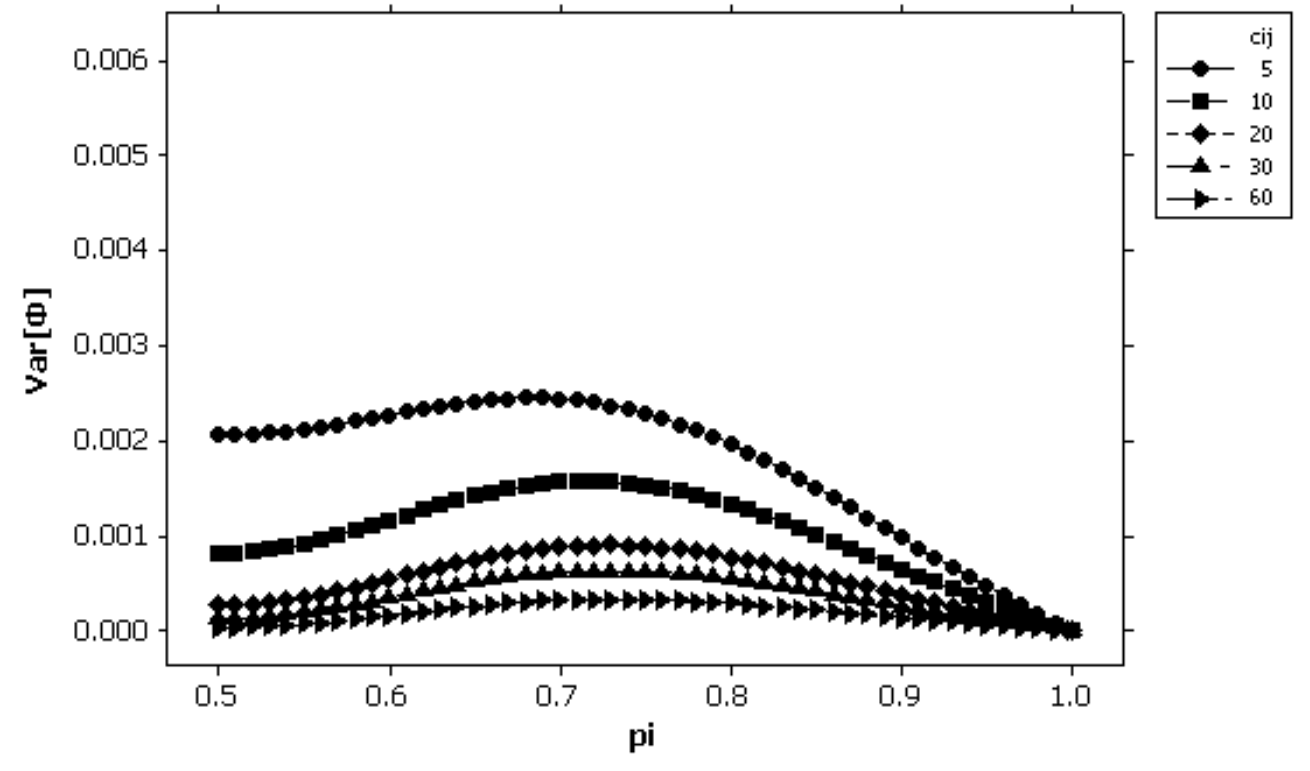


Figure 5.

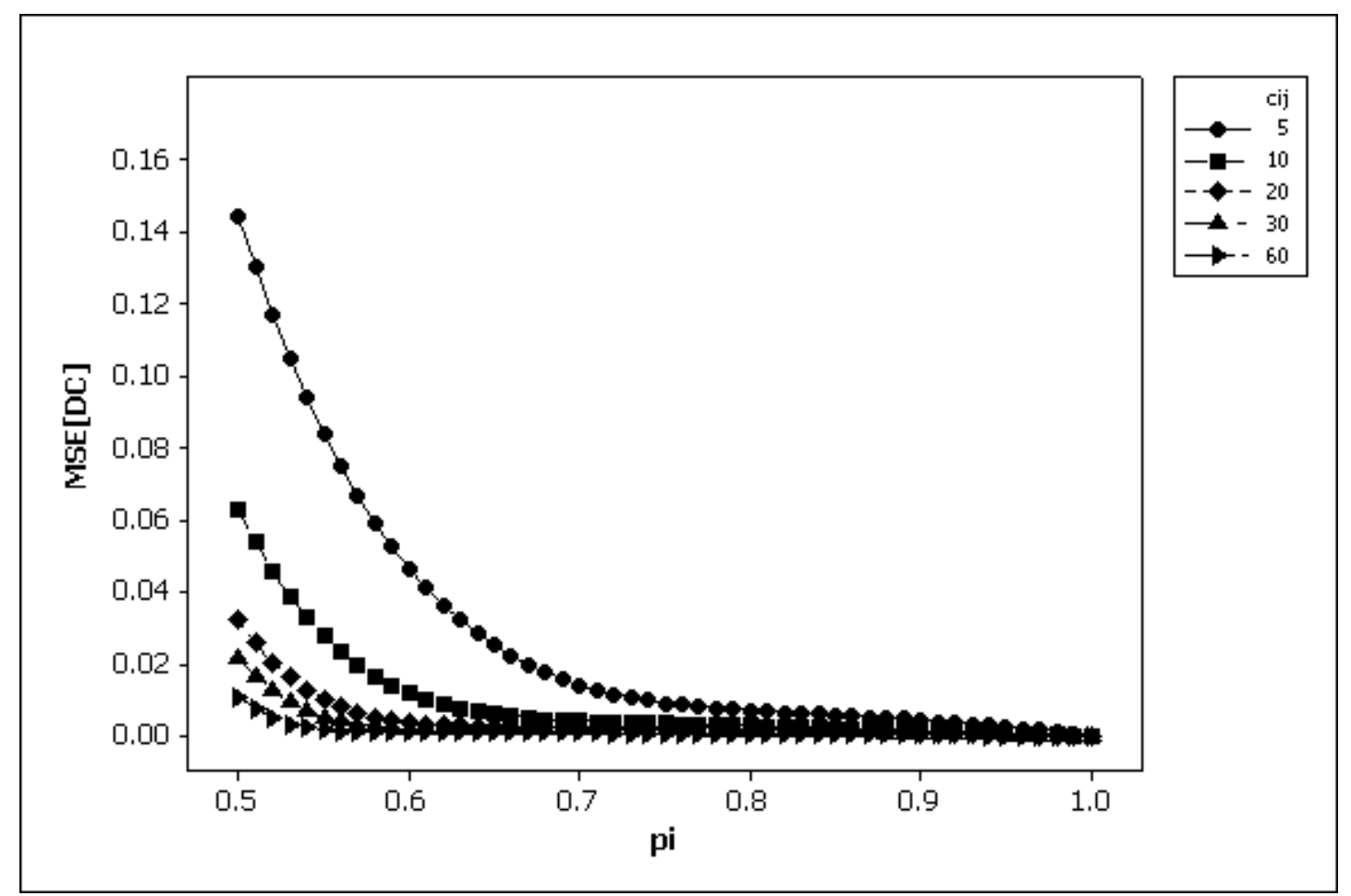


Figure 6.

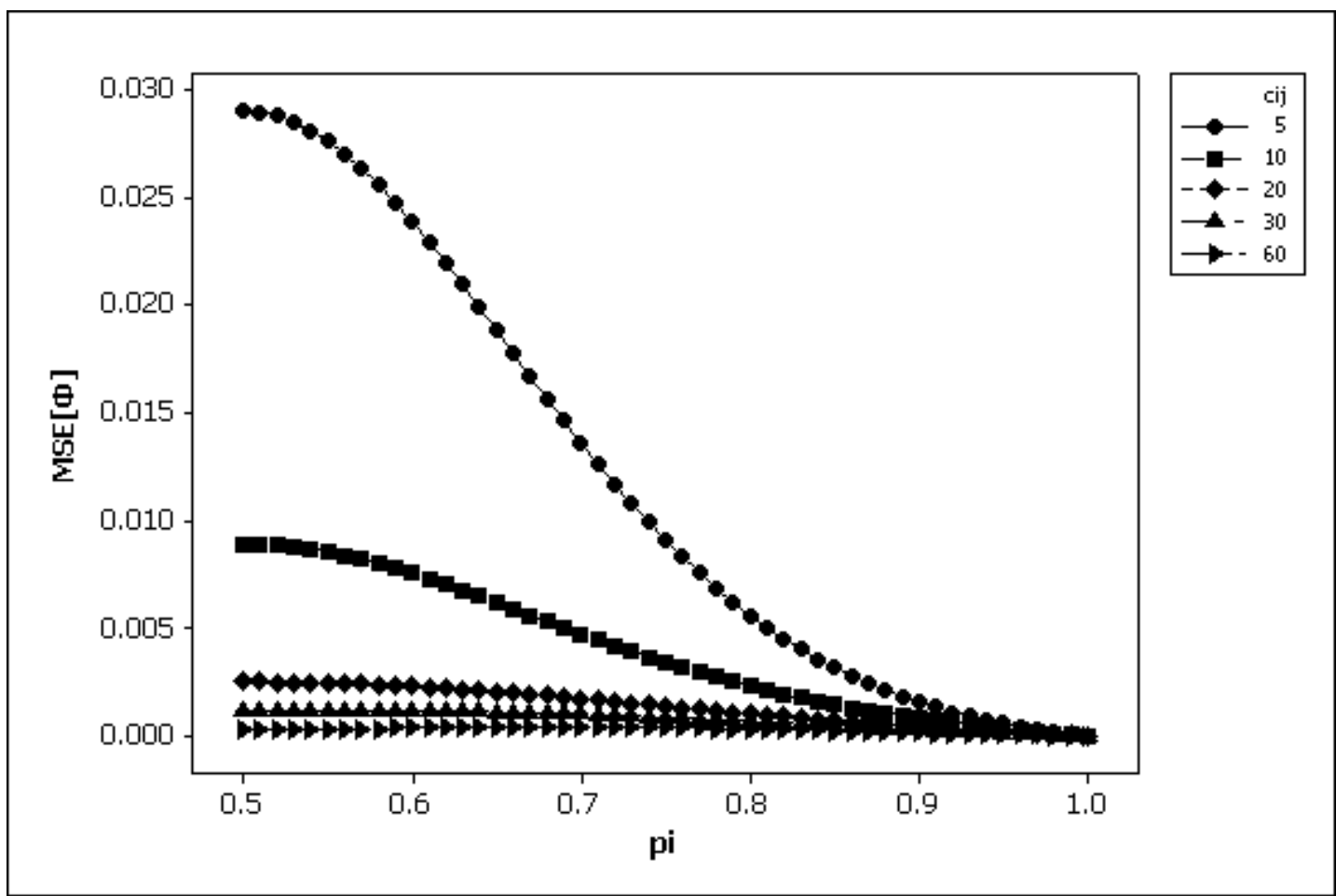

